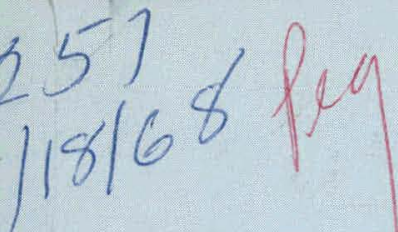

AEC RESEARCH AND DEVELOPMENT REPORT

\title{
COMPUTER PROGRAMS FOR DETERMINING PAYOUT-EYE POSITIONS FOR LAYING FILAMENTS ALONG \\ GEODESIC PATHS ON SURFACES \\ OF REVOLUTION
}

T. W. Bookhart

A. H. Fowler

\section{UNION CARBIDE CORPORATION}

\section{NUCLEAR DIVISION}

OAK RIDGE Y-12 PLANT

operated for the ATOMIC ENERGY COMMISSION under U. S. GOVERNMENT Contract W-7405 eng 26

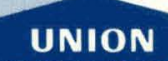

UNION
CARBIDE
OAK RIDGE Y-12 PLANT

P. O. BoX Y

OAK RIDGE, TENNESSEE 37830 


\section{DISCLAIMER}

This report was prepared as an account of work sponsored by an agency of the United States Government. Neither the United States Government nor any agency Thereof, nor any of their employees, makes any warranty, express or implied, or assumes any legal liability or responsibility for the accuracy, completeness, or usefulness of any information, apparatus, product, or process disclosed, or represents that its use would not infringe privately owned rights. Reference herein to any specific commercial product, process, or service by trade name, trademark, manufacturer, or otherwise does not necessarily constitute or imply its endorsement, recommendation, or favoring by the United States Government or any agency thereof. The views and opinions of authors expressed herein do not necessarily state or reflect those of the United States Government or any agency thereof. 


\section{DISCLAIMER}

Portions of this document may be illegible in electronic image products. Images are produced from the best available original document. 
Printed in the United States of America. Available from Clearinghouse for Federal

Scientific and Technical Information, National Bureau of Standards,

U.S. Department of Commerce, Springfield, Virginia 22151

Price: Printed Copy $\$ 3.00$; Microfiche $\$ 0.65$

\section{LEGAL NOTICE}

This report was prepared as an account of Government sponsored work. Neither the United States, nor the Commission, nor any person acting on behalf of the Commission:

A. Makes any warranty or representation, expressed or implied, with respect to the accuracy, completeness, or usefulness of the information contained in this report, or that the use of any information, apparatus, method, or process disclosed in this report may not infringe privately owned rights; or

B. Assumes any liabilities with respect to the use of, or for damages resulting from the use of any information, apparatus, method, or process disclosed in this report.

As used in the above, "person acting on behalf of the Commission" includes any employee or contractor of the Commission, or employee of such contractor, to the extent that such employee or contractor of the Commission, or employee of such contractor prepares, disseminates, or provides access to, any information pursuant to his employment or contract with the Commission, or his employment with such contractor. 


\title{
UNION CARBIDE CORPORATION Nuclear Division
}

\author{
Y-12 PLANT
}

Contract W-7405-eng-26

With the US Atomic Energy Commission

\section{COMPUTER PROGRAMS FOR DETERMINING PAYOUT-EYE POSITIONS FOR LAYING FILAMENTS ALONG GEODESIC PATHS ON SURFACES OF REVOLUTION}

T. W. Bookhart

A. H. Fowler

Oak Ridge, Tennessee

This report. was prepared as an account of Goverament sponsored work. Neither the United States, nor the Commission, nor any person acting on behalf of the Commission:

A. Makes any warranty or representation, expressed or implled, with respect to the accuracy, completeness, or usefulness of the luformation contained in this report, or that the use of any Information, apparatus, method, or process disclosed in this report may not infinge privately owned rights; or

B. Assumes any liabilities with respect to the use of, or for damages resulting from the wae of any information, apparatis, methnn, or process dibclosed in this report.

As used in the above, "person acting on behalf of the Commlsalon" Includes any employee or contractor of the Commission, or employee of such contractor, to the extent that such employee or contractor of the Commission, or employee of auch contractor prepares, disseminates, ur provides accese to, any information murkuant to his employment or contract with the Commission, or his employment with such contractor. 
Document $Y-1620$

Mathematics and Computers

Distribution:

TID-4500

Abbatiello, L. A.

Alvey, H. E.

Ballenger, H. F.

Barbo, P. E. (LASL)

Bell, B. B.

Bernander, N. K.

Blackerby, Jack

Bookhart, T. W. (20)

Bruning, R. L. (GE-Evandale)

Burkhart, L. E.

Butturini, W. G.

Dawson, Ray (Black-Clawson)

Easterday, R. J. (ORGDP)

Ebert, J. W.

Ellingson, R. D.

Evans, G. W.

Forte, N. A. (GE-Evandale)

Foulk, D. L.

Fowler, A. H.

Frye, E. R. (San-Alb)

Garner, B. L. (LRL)

Gilson, J. D. (San-Liv)

Gritzner, V. B.

Hemphill, L. F.

Hensley, C. E.

Horde, G. W. (ORGDP) (2)

Jasny, G. R.

Jerahov, G. E. (Aerojet-Sac)

Jones, F. W.

Jordan, R. G. (ORGDP)

Kahl, K. G.

Keller, C. A. (AEC-ORO)

Kite, H. T.

Knight, C. E.

\author{
LaChance, R. L. (San-Alb) \\ Lang, D. M./Pasquier, L. P. \\ Little, J. C. \\ McCoy, J. C. (Bendix-KC) \\ McLendon, J. D. \\ Meeks, E. J. (AFSC) \\ Miskell, R. V. \\ Mitchel, G.W. \\ Myers, J. P. (San-Alb) \\ Oliver, D. A . (San-Alb) \\ Perry, A. E. \\ Phillips, L. R. \\ Radcliffe, J. N. (Plastics Inst-London) \\ Sestric, M. D. (Bendix-KC) \\ Smith, R. D. \\ Spies, R. J. (LRL) \\ Stoner, H. H. \\ Thomas, R. A. (GE-Waynesboro) \\ Tilson, F. V. \\ Trotter, T. C. \\ Vanstrum, P. R. (ORGDP) \\ Warner, J. F. \\ Waters, J. L. \\ Weaver, R. W. (San-Liv) \\ Wendolkowski, W. S. (ORGDP) \\ Wesley, R. L. \\ Winkel, R. A. (Paducah) \\ Wood, D. C. (2) \\ Yaggi, W. J. \\ Zurcher, E. \\ $Y-12$ Central Files (5) \\ $Y-12$ Central Files (Route) \\ $Y-12$ Central Files $(Y-12 R C)$
}

In addition, this report is distributed in accordance with the category, Mathematics and Computers, as given in the "USAEC Standard Distribution Lists for Unclassified Scientific and Techincal Reports", TID-4500. 


\section{ABSTRACT}

Fortran computer programs have been written for determining a geodesic path on an arbitrary surface of revolution. For this geodesic path on the surface, the corresponding payout-eye locations are calculated so that a machine will lay the filament along this geodesic path. Mandrel geometry andeye clearance are considered in locating the payout eye. The output of the program is a listing of points along the surface and the corresponding payout-eye positions. This information is then processed by an APT postprocessor to produce a punched tape for a numerically controlled filament winder. 


\section{CONTENTS}

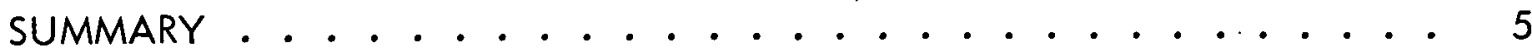

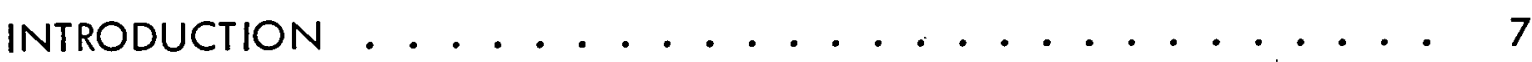

COMPUTER PROGRAM DEVELOPMENT . . . . . . . . . . . 9

Geodesic Path on Surface of Revolution . . . . . . . . . . . 9

Payout-Eye Position ................. . . . 9

Interpolating Along the Geodesic on the Surface . . . . . . . . 15

Locating the Payout Eye to Clear the Mandrel . . . . . . . . . . . 18

Filament Feed . . . . . . . . . . . . . . . 21

Plot of Eye Position . . . . . . . . . . . . . . 22

Computer Program . . . . . . . . . . . . . . . . 24

Program Input ..................... 24

Program Output ................... 24

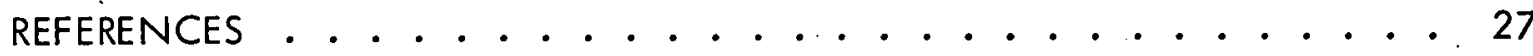

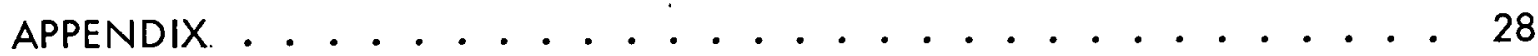

Computer Program . . . . . . . . . . . . . . 28

Main Program WNMAIN ............... 28

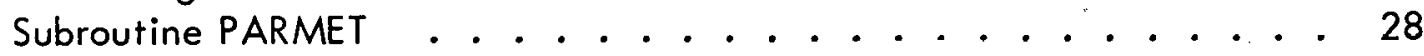

Subroutine DELTHA . . . . . . . . . . . . . . . . . 28

Subroutine ADJUST . . . . . . . . . . . . . . . . 28

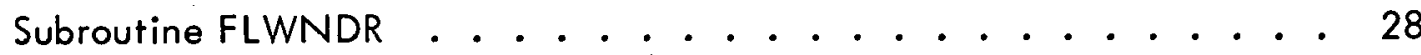

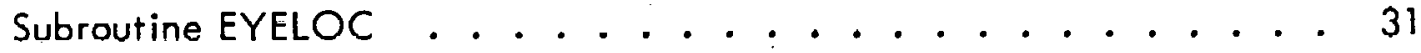

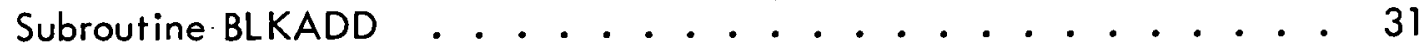

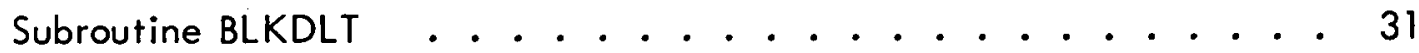

Subroutine RMANDL ...................... 32

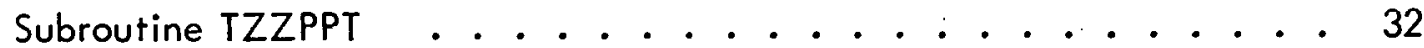

Subroutine AXPLOT . . . . . . . . . . . . . 32

Example of Program Usage . . . . . . . . . . . . . 32

Program Listing . . . . . . . . . . . . . . . . . . . 39

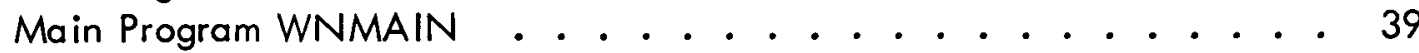

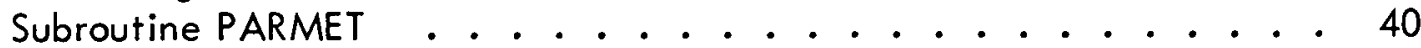

Subroutine DELTHA ................. . . 41

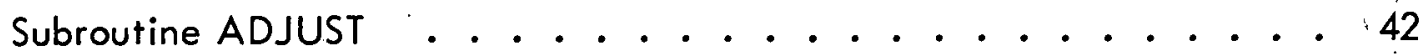

Subroutine FLWNDR .................. 44

Subroutine EYELOC . . . . . . . . . . . . . . . . . . . . . 49

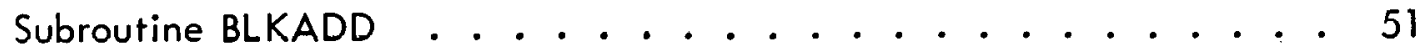

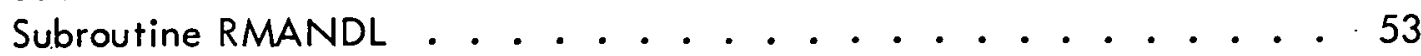

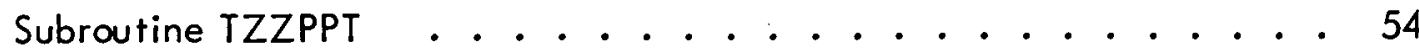

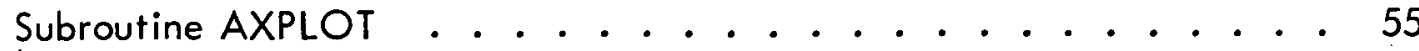




\section{SUMMARY}

Computer routines have been written for determining a geodesic path on an arbitrary surface of revolution and for calculating the filament feed-eye locations so that a machine will lay a filament along the geodesic path. The routines for determining the geodesic path are identical to those reported previously. (1) The method used in determining the geodesic path is to approximate the arbitrary surface by a series of conical and cylindrical sections and compute the path on the individual section. It has been shown $(2)$ that this path converges to the true geodesic path on the original surface as the surface approximation converges.

For a given point $\left(r_{1}, z_{1}, \theta_{1}\right)$ of the geodesic on the surface, the corresponding feedeye position $\left(r_{2}, z_{2}, \theta_{2}\right)$ is found to be:

$$
\begin{gathered}
r_{2}=\sqrt{\left[r_{1} \pm\left(k_{n} \rho \cos \alpha / \sqrt{1+k_{n}^{2}}\right)\right]^{2}+(\rho \sin \alpha)^{2}} \\
z_{2}=z_{1} \pm \rho \sin \alpha / \sqrt{1+k_{n}^{2}}, \text { and } \\
\theta_{2}=\theta_{1}+\tan ^{-1}\left\{\rho \sin \alpha /\left[r_{1} \pm\left(k_{n} \rho \cos \alpha / \sqrt{1+k_{n}^{2}}\right)\right]\right\},
\end{gathered}
$$

where:

$k_{n}$ represents the slope $(d r / d z)$ of the surface at $\left(r_{1}, z_{1}, \theta_{1}\right)$,

$\rho$ the length of the vector from the surface to the eye, and

$\alpha$ the helix angle at $\left(r_{1}, z_{1}, \theta_{1}\right)$. In the \pm expressions,

+ is used when $z$ is increasing (going up part);

- is used for decreasing $z$ (going down part).

The other dimension of interest, the A angle (rotation of the eye about the $r$ axis), is:

$$
A=\tan ^{-1}\left[r_{1} \sin \left(\theta_{2}-\theta_{1}\right) /\left(z_{2}-z_{1}\right)\right] \text {. }
$$

As can be noted from these equations, there is an infinite number of eye positions (one for each value of $p$ ) corresponding to a point of the geodesic on the surface. To uniquely locate the eye position, the clearance of the eye from the mandrel is 
considered. The minimum value of $\rho$ which will allow the eye to clear the mandrel by the desired amount, produces a positive rotation of the mandrel and results in a positive feed of filament from the eye that is used.

An interpolation scheme is utilized for spacing points along the geodesic on the surface so that the machine path will not deviate more than a prescribed tolerance from the geodesic path. This interpolation would be adequate if the eye were located on the surface. However, since the eye is positioned inspace and the vector length from the surface to the eye is continually changing, additional measures are required to better space the eye points. Therefore; routines are included which add additional eye points when a large eye motion occurs and delete points when too closely spaced.

The output of the computer program is a listing of surface points along the geodesic path and the corresponding eye coordinates. These coordinates are also written on magnetic tape in a format of APT GO TO points. This tape can be converted to punched cards and utilized as APT input for a filament-winder postprocessor. 


\section{INTRODUCTION}

Manufacturing techniques for filament winding have advanced from machines mechanically controlled by cams and chains to highly versatile numerically controlled machines. However, to utilize the capabilities of a numerically controlled machine, alogrithms must be developed for computing those machine motions that are necessary to lay a filament along the desired paths. This capability is not currently available in APT or any of the other powerful numerical-control computer systems.

One large class of filament-winding applications involve shapes which are surfaces of revolution. Since a geodesic path on any surface is a stable path, goedesics are often chosen as the desired filament paths. Alogrithms and computer routines were developed earlier $(1)$ for determining a geodesic path on an arbitrary surface of revolution. These routines are useful in designing filament-wound structures andanalyzing their properties. The routines can be extended, however, to compute the machine feed-eye positions for laying a filament along these surface paths. The additional alogrithms for determining these feed-eye positions are developed in this report. The computer program for making the calculations is included. These computer routines have also been incorporated in the APT system as a pre-postprocessor. (3) 
THIS PAGE

WAS INTENTIONALLY

LEFT BLANK 


\section{COMPUTER PROGRAM DEVELOPMENT}

\section{GEODESIC PATH ON A SURFACE OF REVOLUTION}

The approach used in determining a geodesic path on an arbitrary surface of revolution has been reported previously. (1) A brief outline of this approach is as follows: First, approximate the contour of the surface of revolution by a series of short, straight-line segments. When rotated about the axis of revolution, these straight-line segments generate a series of conical and cylindrical sections which approximate the original surface of revolution. Then, by determining the geodesic on the individual conical and cylindrical sections and deriving criteria for crossing from one section to another, the geodesic for the overall surface can be determined. (It has been shown that as the approximated surface converges to the original surface, the geodesic on the approximation converges to the geodesic on the original.)(2)

Computer programs have been written to compute a geodesic path on a surface of revolution. (1) The necessary input for computing the geodesic path is:

1. Points along the contour of the surface to be wrapped (the straight line joining these points form the approximation of the surface).

2. Initial helix angle at an initial point.

3. Number of circuits per pattern and number of mandrel revolutions perpattern (optional).

4. Advance per circuit (optional).

5. Flag indicating whether to adjust or distort the geodesic to produce one having the desired revolutions per circuit.

Given an initial helix angle at an initial point, a geodesic path is computed. If the circuits per pattern and revolution per pattern are specified, the rotation of the path is linearly distorted (if distort is specified) or a new geodesic having this rotation (if adjust is wanted) is computed to produce a path having the desired rotation.

\section{PAYOUT-EYE POSITION}

Once the path on the surface has been found, the problem then is to determine the location of the payout eye so that the filament pulled from the eye is laid along this path on the surface. This information will be procured by computing, for a given point on the surface, the corresponding eye coordinates. The eye axes are shown schematically in Figure 1. 


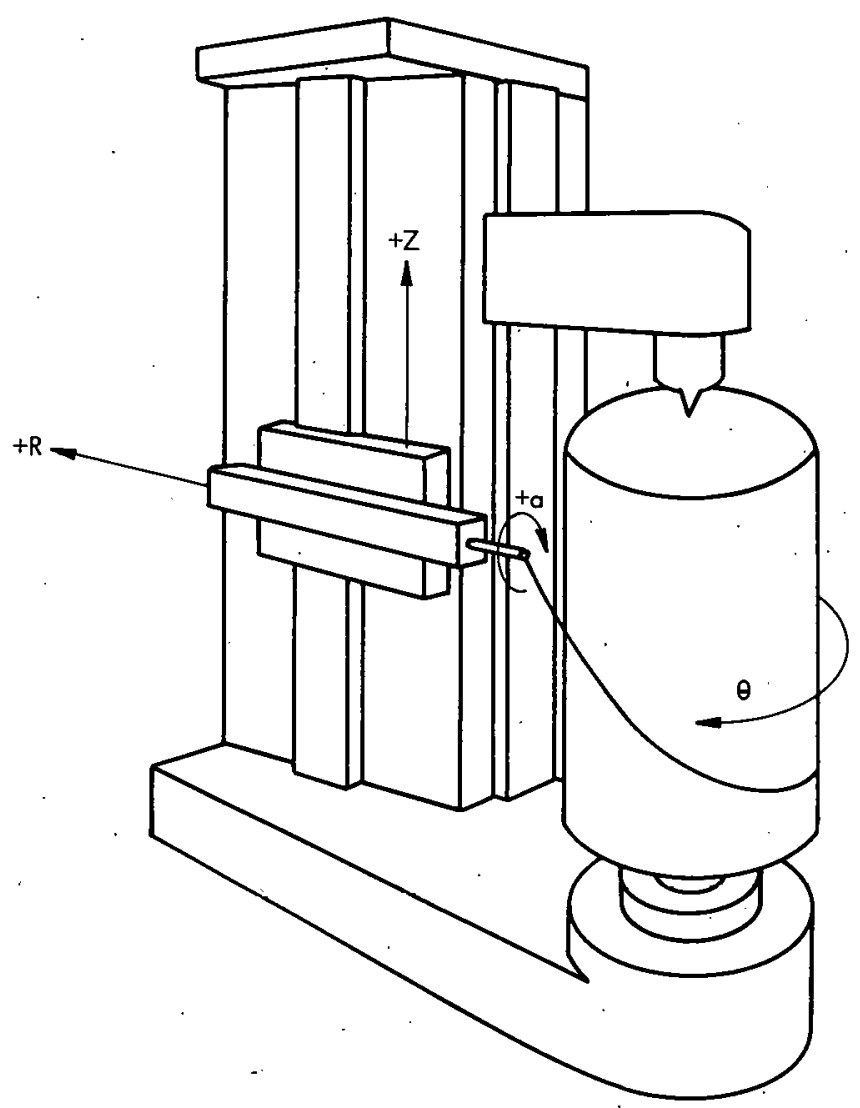

Figure 1. A VERTICAL FILAMENT WINDING MACHINE.

As was done in the previous work, (1) it will be assumed that, locally, the surface to. be wrapped is a cone. Let the equation of the surface be (in cylindrical coordinates):

$$
r=k_{n} z+b,
$$

where $k_{n}$ and $b$ are constants. (Here $k_{n}$ is the slope of the cone $d r / d z$.) Let the geodesic pass through point $P_{1}$ whose coordinates are $\left(r_{1}, z_{1}, \theta_{1}\right)$.

Point $P_{2}$ lies along the vector which is tangent to the geodesic at $P_{1}$, as shown in Figures 2 and 3 . A coordinate frame can be established at $P_{1}$ such that the basis is composed of three orthogonal unit vectors, $\bar{e}_{1}, \bar{e}_{2}$, and $\bar{N}$, where:

$$
\begin{aligned}
& \bar{e}_{1}=\left(k_{n} / \sqrt{1+k_{n}^{2}}\right) \bar{i}+0 \bar{i}+\left(1 / \sqrt{1+k_{n}^{2}}\right) \bar{k} \\
& \text { vector along meridian, } \\
& \bar{N}=\left(1 / \sqrt{1+k_{n}^{2}}\right) \bar{i}+0 \bar{i}-\left(\begin{array}{l}
\left.k_{n} / \sqrt{1+k_{n}^{2}}\right) \\
\text { vector normal to surface, and }
\end{array}\right.
\end{aligned}
$$




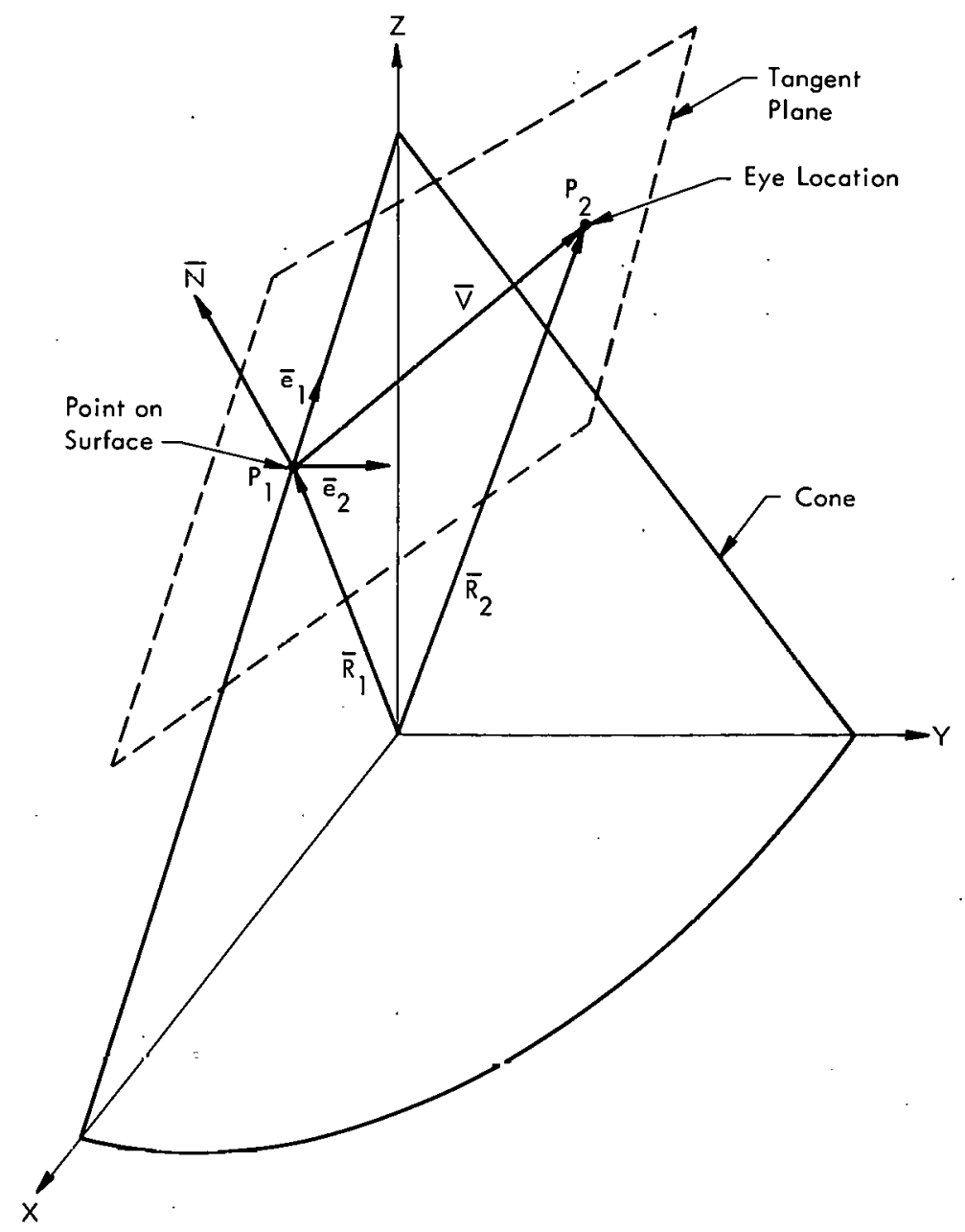

Figure 2. POINT ON THE SURFACE OF A CONE AND CORRE. SPONDING POINT IN THE TANGENT PLANE.

$$
\bar{e}_{2}=\bar{N} \times \bar{e}_{1}=0 \bar{i}+\bar{i}+0 \bar{k} .
$$

Then, the vector from $P_{1}$ to $P_{2}$ is

$$
\bar{V}=(\rho \cos \alpha) \bar{e}_{1}+(\rho \sin \alpha) \bar{e}_{2}+o \bar{N},
$$

where:

$\rho$ represents the length of the vector from $P_{1}$ to $P_{2^{\prime}}$ and

$\alpha$ the helix angle to $P_{1}$. 
12

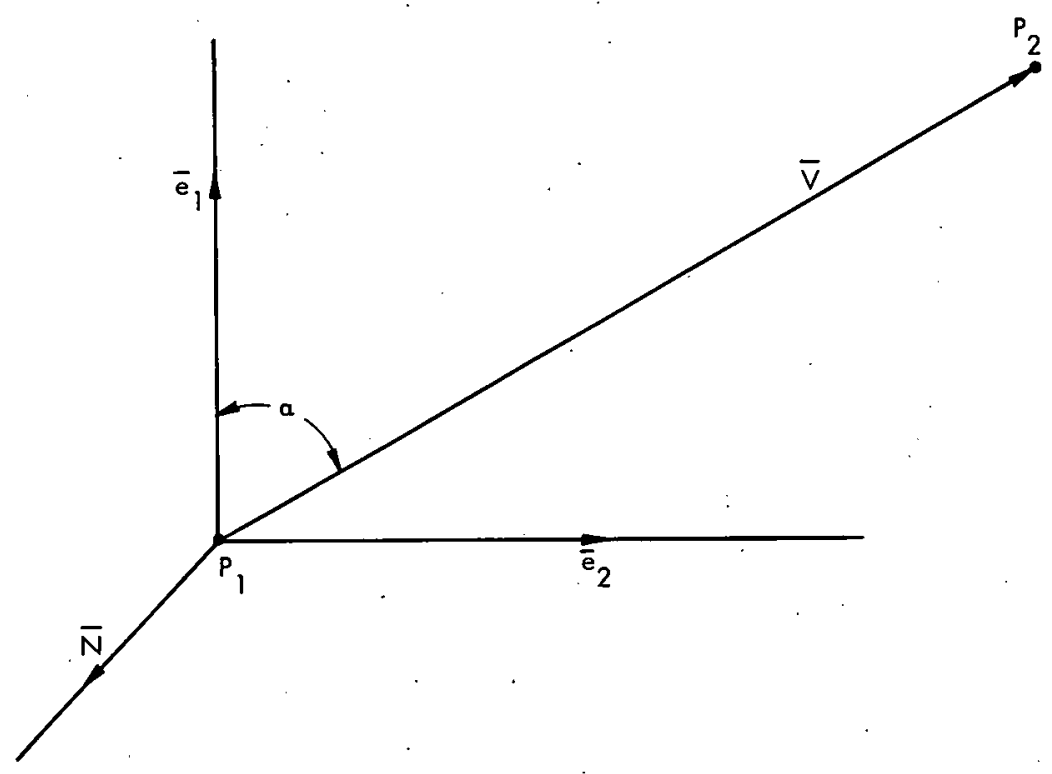

Figure 3. VECTOR FROM THE SURFACE TO THE EYE IN THE TANGENT PLANE - POSITIVE Z DIRECTION.

Thus, the position vector is:

$$
\begin{gathered}
\bar{R}_{2}=\bar{R}_{1}+\bar{V}, \\
=\left[r_{1} \bar{i}+0 \bar{i}+z_{1} \bar{k}\right]+\left[(\rho \cos \alpha) \bar{e}_{1}+(\rho \sin \alpha) \bar{e}_{2}\right], \\
=\left(r_{1} \bar{i}+z_{1} \bar{k}\right)+(\rho \cos \alpha)\left[\left(k_{n} / \sqrt{1+k_{n}^{2}}\right) \bar{i}+\left(1 / \sqrt{1+k_{n}}\right) \bar{k}\right]+ \\
=\left[r_{1}+\left(k_{n} \rho \cos \alpha / \sqrt{1+k_{n}^{2}}\right)\right] \bar{i}+(\rho \sin \alpha) \bar{i}+\text { or } \\
{\left[z_{1}+\left(\rho \sin \alpha / \sqrt{1+k_{n}^{2}}\right)\right] \bar{k} .}
\end{gathered}
$$

If the path were being traced in a negative $z$ direction, as shown in Figure 4, Equation 1 would become:

$$
\bar{V}=(-\rho \cos \alpha) \overline{\mathrm{e}}_{1}+(\rho \sin \alpha) \overline{\mathrm{e}}_{2}
$$




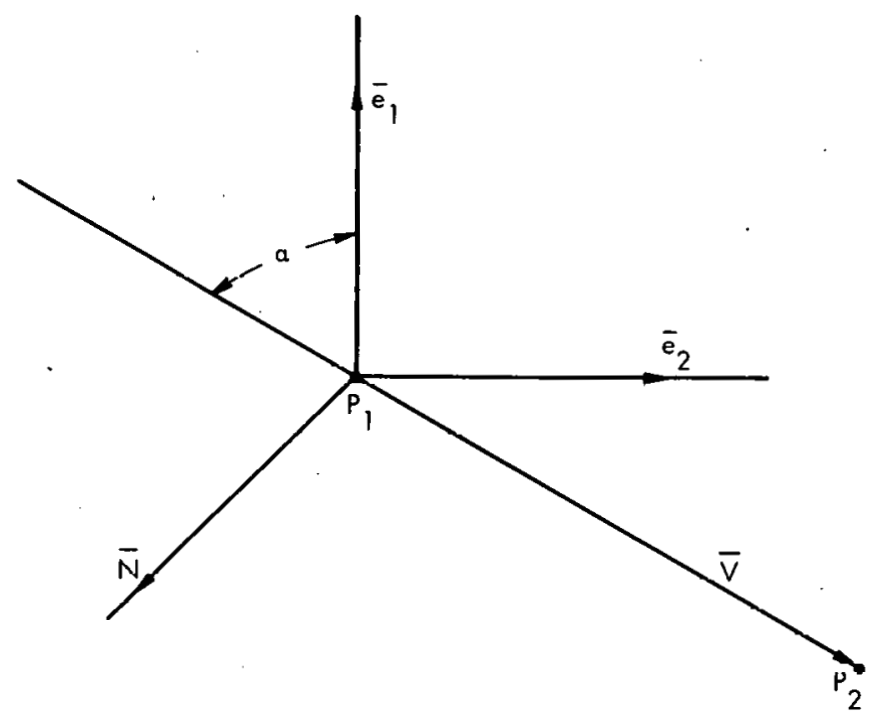

Figure 4. VECTOR FROM THE SURFACE TO THE EYE NEGATIVE Z DIRECTION.

and Equation 2 would be changed to :

$$
\begin{aligned}
\bar{R}_{2}=\left[r_{1}-\left(k_{n} \rho \cos \alpha / \sqrt{1+k_{n}^{2}}\right)\right] \bar{i}+(\rho \sin \alpha) \bar{j}+ \\
\cdot\left[z_{1}-\left(\rho \cos \alpha / \sqrt{1+k_{n}^{2}}\right)\right] \bar{k} .
\end{aligned}
$$

In any case, $P_{2}=\left(r_{2}, z_{2}, \theta_{2}\right)$,

where:

$$
\begin{gathered}
r_{2}=\sqrt{x_{2}^{2}+y_{2}^{2}} \text {, or } \\
r_{2}=\sqrt{\left[r_{1} \pm\left(k_{n} \rho \cos \alpha / \sqrt{1+k_{n}^{2}}\right)\right]^{2}+(\rho \sin \alpha)^{2}}, \\
z_{2}=z_{1} \pm \rho \cos \alpha / \sqrt{1+k_{n}^{2}}, \text { and } \\
\theta_{2}=\theta_{1}+\tan ^{-1}\left\{\rho \sin \alpha /\left[r_{1} \pm\left(k_{n} \rho \cos \alpha / \sqrt{1+k_{n}^{2}}\right)\right]\right\} .
\end{gathered}
$$


In the expression, \pm+ is for increasing $z$, and - is for decreasing $z$.

Thus, corresponding to $\left(r_{1}, z_{1}, \theta_{1}\right)$ on the surface, as shown in Figure 5 , the corresponding eye location is $\left(r_{2}, z_{2}, \theta_{2}\right)$ whose value is given by. Equations 5,6 , and 7.

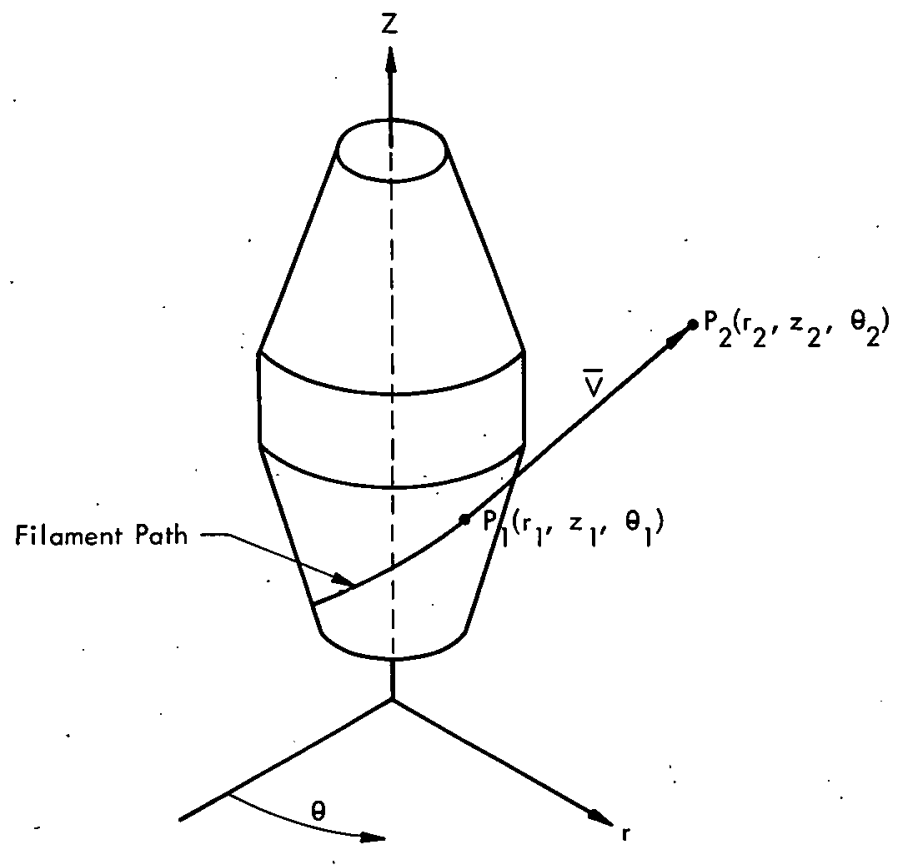

Figure 5. VECTOR FROM THE SURFACE TO THE EYE ON A SURFACE OF REVOLUTION.

The fourth axis of interest is the rotation of the payout eye about its axis. The filament band is to be fed through a slit which will be normal to the vector from surface to eye. With $P_{2}$ located in the $X-Z$ plane (axis of the feed eye along the $\bar{i}$ vector), the vector from surface to eye becomes (Figure 6 shows the projection of this vector into the $X-Y$ plane):

$$
\begin{gathered}
\bar{V}=\left(x_{2}-x_{1}\right) \bar{i}+\left(y_{2}-y_{1}\right) \bar{i}+\left(z_{2}-z_{1}\right) \bar{k}, \\
=\left[r_{2}-r_{1} \cos (-\Delta \theta)\right] \bar{i}+\left[0-r_{1} \sin (-\Delta \theta)\right] \bar{i}+\left(z_{2}-z_{1}\right) \bar{k} \text { or } \\
=\left[r_{2}-r_{1} \cos (\Delta \theta)\right] \bar{i}+\left[r_{1} \sin (\Delta \theta)\right] \bar{i}+\left(z_{2}-z_{1}\right) \bar{k},
\end{gathered}
$$

where:

$$
\Delta \theta=\theta_{2}-\theta_{1}
$$




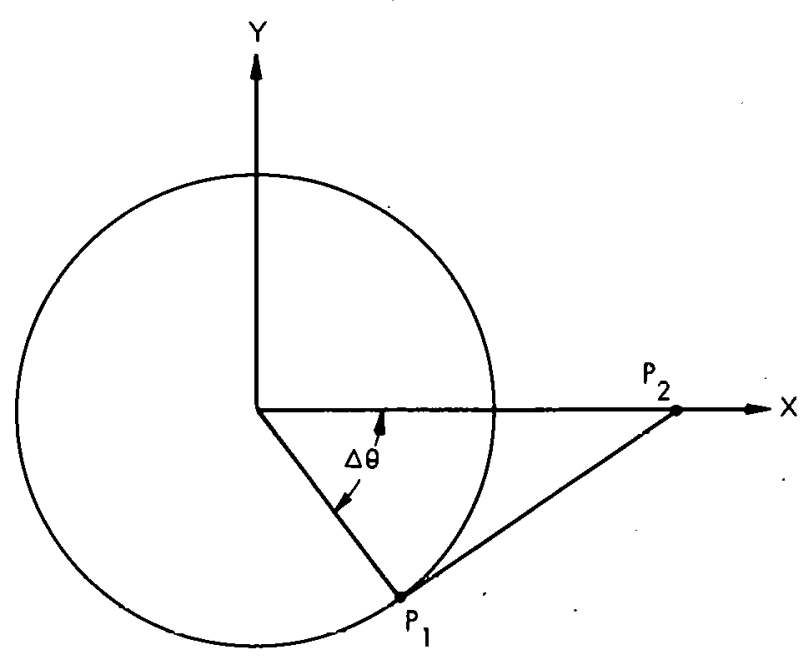

Figure 6. PROJECTION OF A FILAMENT VECTOR INTO THE X-Y PLANE.

Let $\bar{w}$ be the vector along the slit in the payout eye. Then $\bar{w}$ will be perpendicular to $\bar{V}$ and $\bar{i}$, or:

$$
\begin{aligned}
\bar{w} & =\bar{V} \times \bar{i} \\
& =\left(z_{2}-z_{1}\right) \bar{i}-(r \sin \Delta \theta) \bar{k} .
\end{aligned}
$$

The angle the eye makes with the $X-Y$ plane (the " $A$ " angle) can then be found by:

$$
\begin{aligned}
\cos A & =\bar{w} \cdot \bar{i} /(|\bar{w} \| \bar{i}|), \\
& =\left(z_{2}-z_{1}\right) / \sqrt{\left(z_{2}-z_{1}\right)^{2}+\left(r_{1} \sin \Delta \theta\right)^{2}} .
\end{aligned}
$$

Thus, Angle $A$ can be found by:

$$
A=\tan ^{-1}\left\{\left[r_{1} \sin \left(\theta_{2}-\theta_{1}\right)\right] /\left(z_{2}-z_{1}\right)\right\}
$$

\section{INTERPOLATING ALONG THE GEODESIC ON THE SURFACE}

A numerically controlled machine moves from one commanded position to another such that the motion along each axis is linear with in that axis. For the winder, the motion the eye makes will be linear in $r, z$, and $\theta$ in moving from one point to another. Hence, the path traced will not follow a geodesic except in the special case where the surface is cylindrical. To ensure that the path will not deviate more 
than some preset tolerance from the geodesic, it may be necessary to interjectadditional points along the geodesic.

In determining an interpolation scheme, the developed surface is utilized (Figure 7): (1) The geodesic path from $P_{1}$ to $P_{2}$ is a straight line on the developed

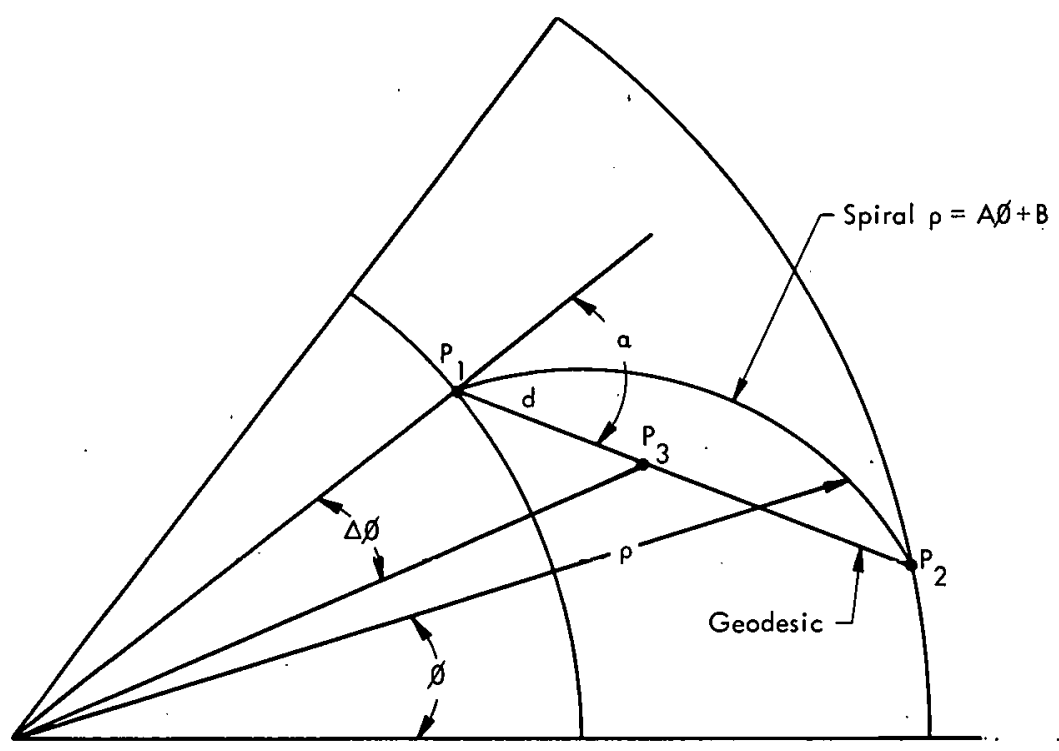

Figure 7. MACHINE MOTION SHOWN ON A DEVELOPED SURFACE.

surface while the machine path will be that of a spiral $\rho=A \varphi+B$. The radius of curvature of the spiral is computed at $P_{1}$ and used to determine the maximum step that can be taken. If the allowable step is less than the distance from $P_{1}$ to $P_{2}$, then a new point, $P_{3}$, is added and the process is continued.

The radius of curvature of the spiral can be found by:

$$
R_{c}=\left[\rho^{2}+(d \rho / d \varphi)^{2}\right]^{3 / 2}, /\left[\rho^{2}+2(d \rho / d \varphi)^{2}-\rho\left(d^{2} \rho / d \varphi^{2}\right)\right] .
$$

Here,

$$
\begin{gathered}
d \rho / d \varphi=\rho \cos \alpha / \sin \alpha, \\
d^{2} \rho / d \varphi^{2}=0, \text { and } \\
\rho=\left(f_{n} /\left|k_{n}\right|\right) r_{1},
\end{gathered}
$$


where:

$\alpha$ represents the helix angle,

$k_{n}$ the slope of the cone,

$f_{n}=\sqrt{1+k_{n}^{2}}$

$r_{1}$ the radius of surface at $P_{1}$.

Then, the radius of curvature becomes:

$$
\begin{aligned}
R_{c} & =o\left\{1 /\left[\sin \alpha\left(1+\cos ^{2} \alpha\right)\right]\right\}, \\
& =f_{n} r_{1}^{4} /\left[\left|k_{n}\right| c\left(2 r_{1}^{2}-c^{2}\right)\right],
\end{aligned}
$$

where:

$$
c=r_{0} \sin \alpha_{0} \quad\left(\alpha_{0} \text { is the helix angle at some point whose radius is } r_{0}\right) .
$$

The maximum step that can be taken with the distance between a circle of radius, $R_{c^{\prime}}$ and the line not exceeding some tolerance, $t$, is found (see Figure 8 ) to be:

$$
d=2 \sqrt{2 R_{c} t-t^{2}}
$$

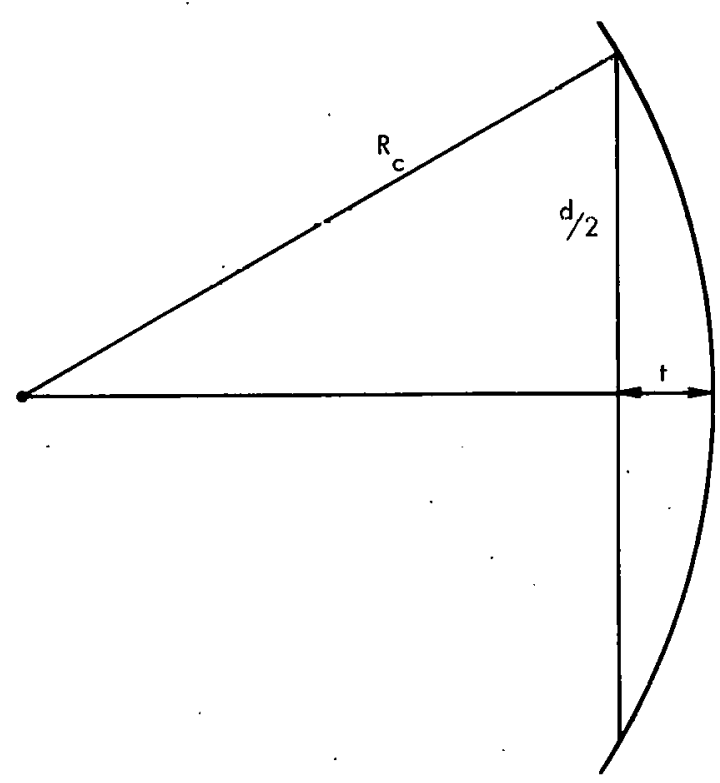

Figure 8. DISTANCE BETWEEN THE CIRCLE OF RADIUS R AND A CORD THAT EQUALS 
The distance, $d$, can be used to determine the point $P_{3^{\prime}}$ thus:

$$
\begin{gathered}
d / \sin \Delta \varphi=\left[\left(f_{n} /\left|k_{n}\right|\right) r_{1} / \sin (\alpha-\Delta \varphi)\right], \\
\tan \Delta \varphi=\left\{d \sin \alpha /\left[\left(f_{n} /\left|k_{n}\right|\right) r_{1}+d \cos \alpha\right]\right\}, \text { or } \\
\Delta \dot{\varphi}=\tan ^{-1}\left\{d c /\left[\left(f_{n} /\left|k_{n}\right|\right) r_{1}^{2}+d \sqrt{r_{1}^{2}-c^{2}}\right]\right\} .
\end{gathered}
$$

From $\Delta \varphi$, the point $P_{3}=\left(r_{3}, z_{3}, \theta_{3}\right)$ can be found:

$$
\begin{aligned}
& \theta_{3}=\theta_{1}+\left(f_{n} /\left|k_{n}\right|\right) \Delta \varphi, \\
& r_{3}=c / \sin (\alpha-\Delta \varphi), \text { and } \\
& z_{3}=\left(r_{1}-r_{n}\right) / k_{n}-z_{n} .
\end{aligned}
$$

Equations $12-15$ are derived for the cone when $r_{1}<r_{2}$ (see Figure 7). When going the other direction, $r_{1}>r_{2}$, the equation becomes:

$$
\begin{gathered}
\Delta \varphi=\tan ^{-1}\left\{d c /\left[\left(f_{n} /\left|k_{n}\right|\right) r_{1}^{2}-d \sqrt{r_{1}^{2}-c^{2}}\right]\right\} \text {, and } \\
r_{3}=c / \sin (\alpha+\Delta \varphi) .
\end{gathered}
$$

\section{LOCATING THE PAYOUT EYE TO CLEAR THE MANDREL}

In a previous section, equations were developed for locating the payout eye corresponding to a point on the surface. Equations $5-8$ showed that the eye could be located anywhere along the tangent vector and that the filament would lay on the surface at the desired point. To uniquely locate a position for the eye, another factor must be taken into consideration - the clearance of the eye from the mandrel.

For a tangent vector of length $\rho$, the coordinates of the eye can be found. With the payout geometry as shown in Figures 9 and 10 , the coordinates of $P_{2}$ and $P_{3}\left(P_{4}\right.$ and $P_{5}$ are used when $P_{1}$ is located below the maximum diameter of the part) are then 


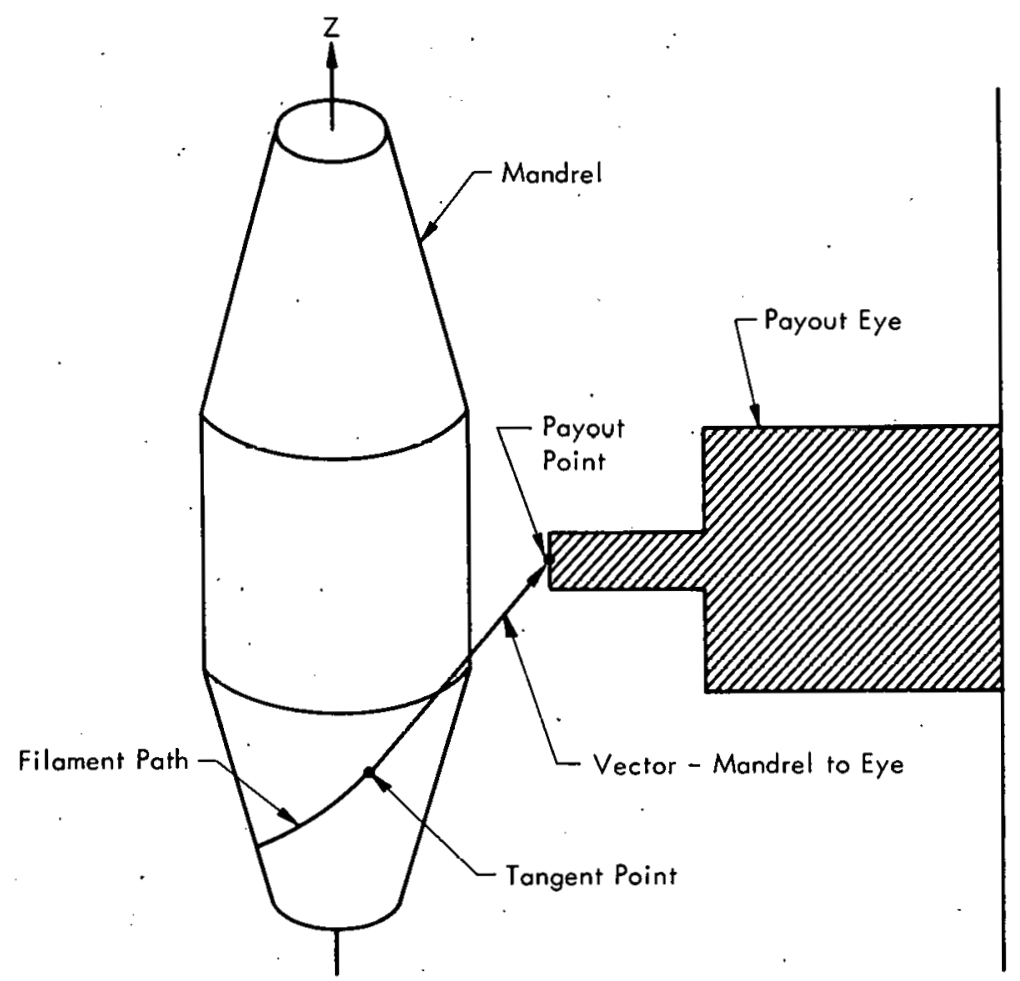

Figure 9. RELATION OF THE PAYOUT EYE TO THE MANDREL.

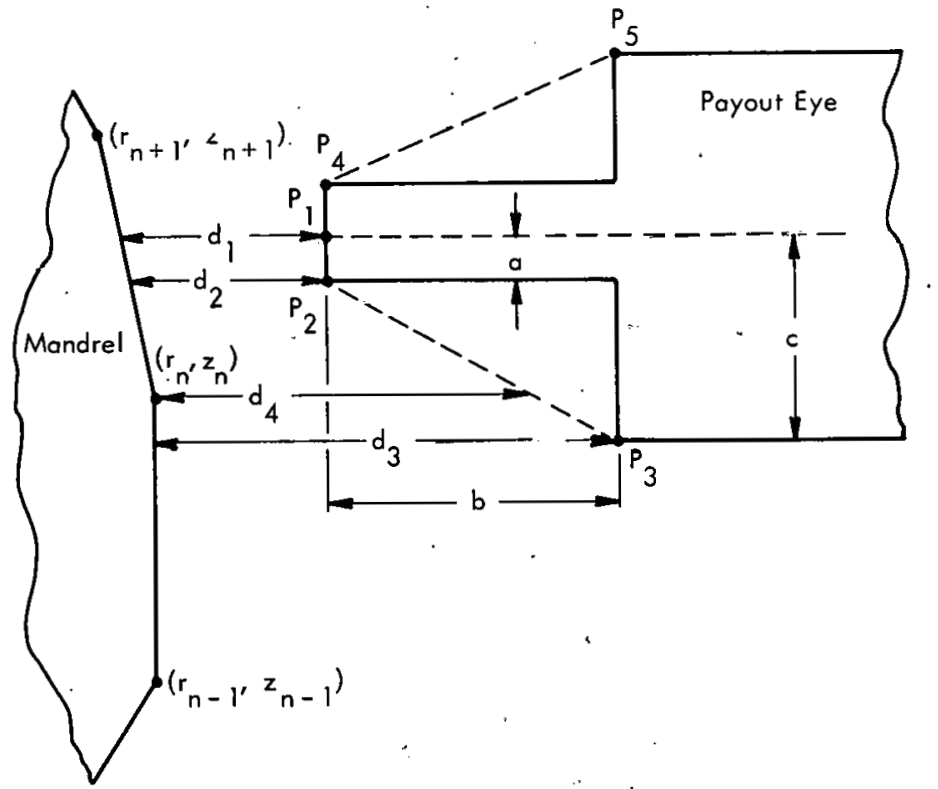

Figure 10. ENLARGED VIEW OF THE PAYOUT EYE AND MANDREL. 
determined. Using these coordinates, the horizontal clearances $d_{1}, d_{2}$, and $d_{3}$ can be calculated. If a point defining the mandrel is located between $P_{2}$ and $P_{3}$, the horizontal distance from the point on the mandrel and a line connecting $P_{2}$ and $P_{3}$ is also computed (distance $d_{4}$, as shown in Figure 10). If any of these distances are less than the desired clearance, the vector length, $o$, is increased by an amount $\Delta \rho$ and the procedure continued until all points clear by the desired amount. If all points clear initially, the vector length, $\rho$, is decreased by $\Delta \rho$ until a further reduction in $\rho$ would produce a clearance less than desired, produce a negative $\Delta \theta$ of the eye, or produce a negative feed of filament through the eye.

This procedure defines the payout point for a given surface point and allows the eye to remain as close as possible to the surface while maintaining a specified horizontal clearance. Staying close to the surface in most cases results in a minimum motion of the eye. There have been cases, however, where this procedure has resulted in a sudden large lengthening of the vector, producing large delta motions of the eye.

Most of these cases were results of wrapping with a low helix angle where shaft interference became a problem. In these cases it would have been desirable to have some of the points preceding this large change with vector lengths greater than that of minimum clearance. This condition could be accomplished by reworking the previous information when a situation such as this arises. At this time, no such routine has been developed to rework the information.

A routine has been written, however, for interjecting additional eye points when a large $\Delta \theta$ of the eye is encountered. If the $\Delta \theta$ from one computed eye position to the next is greater than DTMAX (DTMAX is initialized in subroutine FLWNDR and is currently set at $45^{\circ}$ ), then subroutine BLKADD is called to add additonal eye positions. Additional eye points are computed for $\Delta \dot{\theta}$ (eye) in increments of 18 degrees (increments of DBA which is currently set at $18^{\circ}$ in subroutine BLKADD). This calculation is accomplished by determining the vector length (surface to eye) which will produce the desired $\theta$ (eye) coordinate. The remaining eye coordinates are then computed using this vector length. If this eye position will not produce the desired clearance, the $r$ coordinate is set to the minimum value which will give the clearance. Thus, the points added by this routine, if the $r$ coordinate is altered, may not lie along the proper tangent vector. Hence, points added by this routine are preceded by an asterisk in the output listing.

Another undesirable situation which can occur by using the shortest length vector is that of point spacing. The interpolation scheme, previously described, spaces the points along the geodesic on the surface to assure a given tolerance. This scheme would be adequate if the eye were located on the surface. However, since the eye is located in space, equally spaced surface points can produce unequally spaced eye location points. When using a numerically controlled machine, points too closely spaced can slow down the operation since there is a finite minimum block execution time (tape-read time or interpolation time). 
A routine, BLKDLT, was written to eliminate points whose eye positions are too closely spaced. This adjustment is accomplished by defining a five-dimensional motion vector whose components are in a sense normalized, that is:

$$
\overline{\Delta V}=(\Delta r, \Delta z, \Delta \mathrm{l}, \Delta \theta / 15, \Delta \mathrm{A} / 25),
$$

where:

$\Delta r$ represents the delta motion of the $r$ axis,

$\Delta z$ the delta motion of the $z$ axis,

$\Delta \mathrm{l}$ the filament fed,

$\Delta \theta$ the delta mandrel rotation (degrees), and

$\Delta \mathrm{A}$ the delta eye rotation (degrees).

The norm of this motion vector is defined to be:

$$
|\overline{\Delta V}|=|\Delta r|+|\Delta z|+|\Delta I|+|\Delta \theta / 15|+|\Delta A / 25| .
$$

The eye positions, as shown on the output listing, are examined and points eliminated until the resulting motion is such that:

$$
|\overline{\Delta V}| \geq 1 \text {. }
$$

These remaining points are then written on magnetic tape in the format of APT GO TO points. This tape can be converted to punch card and the cards processed by an APT postprocessor .

\section{FILAMENT FEED}

In trying to maintain a constant rate of filament being fed from the eye, it is necessary to compute the length of filament fed as the eye moves from one point to another. If the eye moves from $\mathrm{P}_{1}$ to $\mathrm{P}_{2}$, as shown in Figure 11 , then the filament that is fed can be determined, that is:

$$
\begin{aligned}
& 1+\rho_{2}=f \mid+o_{1} \text { or } \\
& f l=i+\left(\rho_{2}-\rho_{1}\right),
\end{aligned}
$$




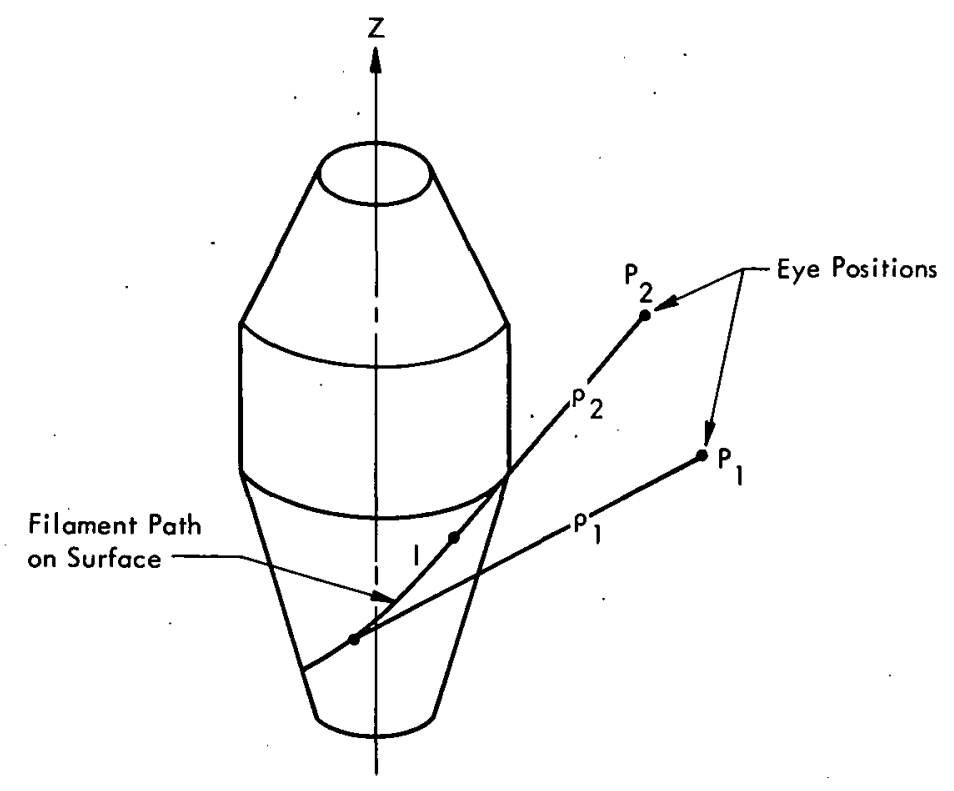

Figure 11. FEED-EYE POSITIONS BEFORE AND AFTER MOTION.

where:

fl represents the filament fed from the eye,

I the filament laid on the surface,

$o_{1}$ the vector length at the start of motion, and

$\rho_{2}$ the vector length at the end of motion.

The filament laid on the surface is computed in the routines which determine the path on the surface. (1)

\section{PLOT OF THE EYE POSITION}

In order to better visualize the wrap, computer routines have been written to draw two-dimensional plots of the surface path and the corresponding path of the payout eye. Figures 12 and 13 are illustrations of this type of plot. Shown in Figure 12 is $Z$ (the carriage position) versus $\theta$ (the mandrel rotation) for one circuit. The inside plot is the path on the surface and the outer plot is the payout eye, with a line joining corresponding surface and eye points. Figure 13 shows $R$ (the cross carriage) versus $Z$. These plots are for a 55-degree helix-angle wrap pattern on the mandrel shown in Figure 14. 


$$
\alpha t
$$




\section{COMPUTER PROGRAM}

The computer program consists of a main program and 10 subroutines written in Fortran II language. These routines are described in the Appendix. In addition, several plotting routines for the Gerber Scientific Plotter $(4)$ are utilized in constructing the plots previously mentioned.

Program Input

The input to the computer program consists of the following:

1. The number of points used in defining the surface.

2. Coordinates of the points defining the surface (straight lines joining these points form the approximation of the surface) in order of increasing $z$.

3. Desired clearance (eye to mandrel).

4. Tolerance for surface interpolation (allowable deviation of spiral to geodesic).

5. Shaft radii.

6. The number of geodesics to be wrapped, and for each geodesic: (a) coordinates of the initial point, (b) initial helix angle, (c) advance per circuit (revolutions), (d) number of circuits to be wrapped, (e) number of circuits per pattern, ( $f$ ) number of revolutions per pattern, (g) flag indicating whether to adjust the helix angle or distort the geodesic, (h) flag indicating if plot is wanted, and (i) scale of plnt (if desired).

The format for the program input is shown in the Appendix.

If the number of circuits per pattern and revolution per pattern are not specified (left blank), the geodesic wrapped will be that determined by the initial conditions. However, if the circuits per pattern and revolutions per pattern are specified, a new geodesic (if an adjustment is wanted) will be found or the rotation of the computed geodesic distorted (if a distort is wanted) to obtain a path having the desired number of revolutions per circuit.

\section{Program Output}

There are two listings for each geodesic computed. The first list shows the input data specifying the geodesic. Also shown on the first list is the total mandrel rotation (degrees) for a circuit, the length of filament laid on the surface during a circuit, and the distortion factor (the computed rotation is multiplied by this factor to achieve the desired number of revolutions per circuit. 




$121252 \mathrm{~A}$

Figure 14. TEST MANDREL WOUND ON A NUMERICALLY CONTROLLED WINDER. 
The second listing shows the eye positions corresponding to points along the geodesic on the surface. This list includes the coordinates of the surface point $\left(r_{1}, z_{1}, \theta_{1}\right)$, the corresponding eye coordinates $\left(r_{2}, z_{2}, \theta_{2}\right)$, the $A$ angle of the eye, the length of the vector from the surface point to the eye, the filament fed as the eye moves from the previous to the present position, the filament laid on the surface during this motion, and the angular positions, $\theta$ and $A$, in revolutions. Interpolated eye positions (interjected by subroutine BLKADD) are preceded by asterisks.

The first surface point and eye position shown in the list will be located at the maximum diameter of the mandrel. The second eye position shown is the point in space corresponding to that same surface point; that is, the first motion of the eye is from a starting point on the surface to a point in space. This motion is for setup purposes. The eye starts at a known point on the surface and then preceeds through the circuit. The final point listed for the circuit is the same as that of the first space point.

An example of the program output is included in the Appendix. 


\section{REFERENCES}

(1) Bookhart, T. W. and Fowler, A. H.; Geodesic Paths on Surfaces of Revolution: A Computer-Aided Filament Winding Design Program, Y-1660; Union Carbide Corporation-Nuclear Division, Y-12 Plant, Oak Ridge, Tennessee; to be published.

(2) Gold, S. P.; Filament Winding a Surface of Revolution, SCL-DR-65-102; Sandia Corporation-Livermore Laboratory, Livermore, California; February 1966.

(3) Bookhart, T. W., Easterday, R. J., Fowler, A. H., and Miskell, R. V.; An Extension of APT for Producing Input Data for a Four-Axis Filament-Winder Postprocessor (Union Carbide APT Filament-Winding Pre-Postprocessor - UCAFIP), $\overline{Y-1653 ;}$ Union Carbide Corporation-Nuclear Division, Y-12Plant, Oak Ridge Tennessee; to be published.

(4) Fowler, A. H. and Wilson, C. W.; Cubic Spline, A Curve-Fitting Routine, $Y-1400$ (Revision 1), pp 104-109; Union Carbide Corporation-Nuclear Division, Y-12 Plant, Oak Ridge, Tennessee; June 28, 1966. 


\section{APPENDIX}

\section{COMPUTER PROGRAM}

The computer program consists of a main program and ten subroutines written in Fortran 11. Also, certain plotting routines $(4)$ for the Gerber Scientific Plotter are utilized in constructing the plots described earlier. The input format is shown in Figure $A-1$; the deck arrangement is presented in Figure A-2. The Fortran routines are described in the sections that follow.

\section{Main Program WNMAIN}

This is the main computer program for determining the winder-eye locations. Payouteye and vector parameters are initialized here and the input data are read in. Routines for computing the geodesic on the surface and determining the payout-eye location are then called. If plots are wanted, the plotting routine is called.

\section{Subroutine PARMET}

This routine computes various parameters for the conical and cylindrical sections that make up the surface. These parameters are stored and used by the other routines called.

\section{Subroutine DELTHA}

This routine determines the delta theta (mandrel rotation) on the surface for each section and the total rotation for one circuit. The length of filament laid is also computed. The subroutine argument is the geodesic number.

\section{Subroutine ADJUST}

This routine is called to adjust the initial helix angle in order to obtain a geodesic having a predetermined number of revolutions per circuit. The first argument of ADJUST is the geodesic number, the second is the desired number of revolutions per pattern, the third is the desired number of circuits per pattern, the fourth is the number of revolutions per circuit of the geodesic as initially specified, the fifth is the maximum difference that will be allowed between the number of revolutions per circuit of a new geodesic and the revolutions per circuit desired, and the sixth is a flag indicating to the calling program whether or not a geodesic could be found having the desired number of revolutions per circuit.

\section{Subroutine FLWNDR}

In this routine, the path on the surface as computed in DELTHA is followed and the routine for computing payout-eye location is called when desired. Path interpolation is performed when the spiral path and geodesic deviate by more than the 


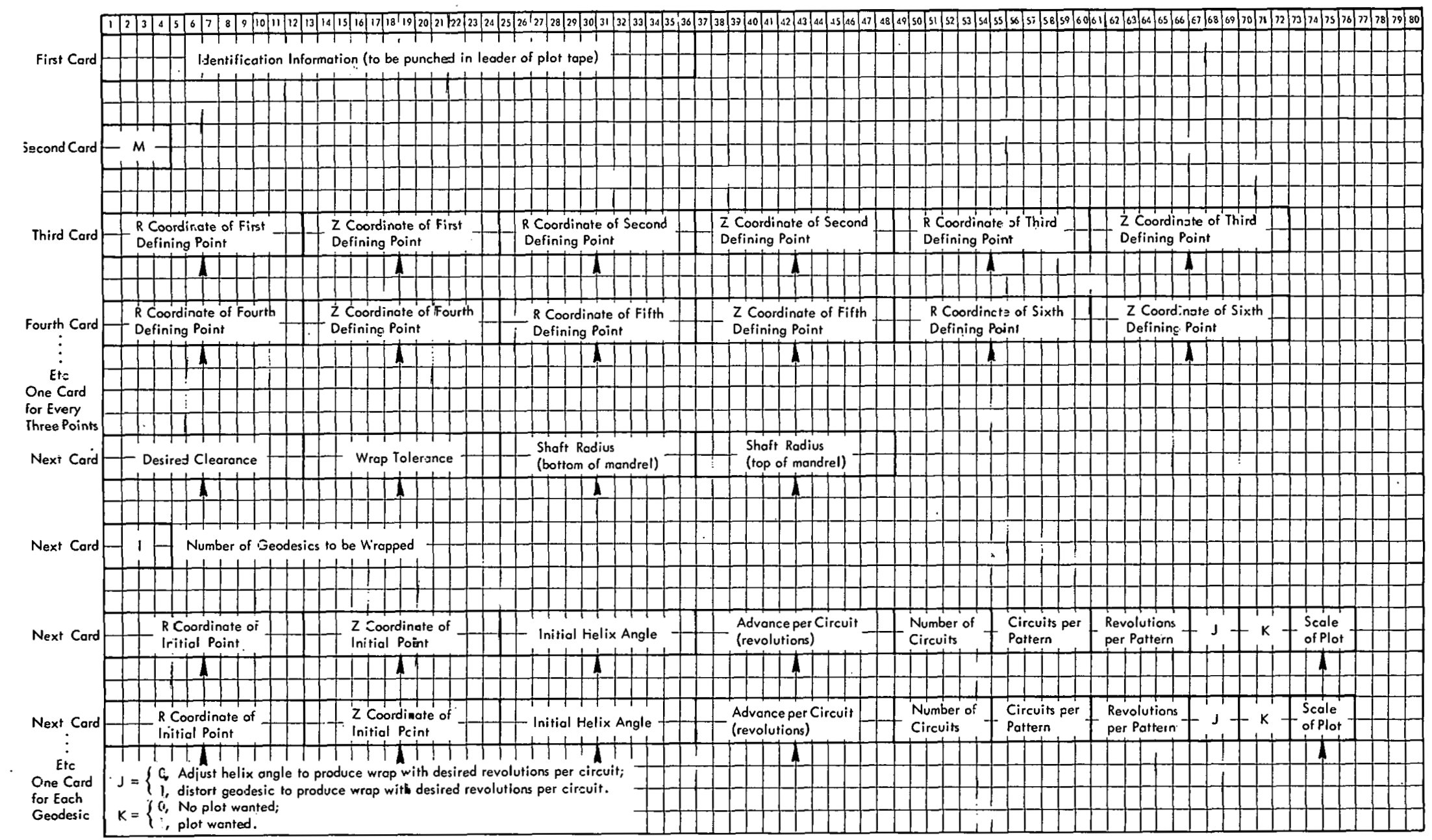

Figure A-1. PROGRAM INPUT FORMAT. 


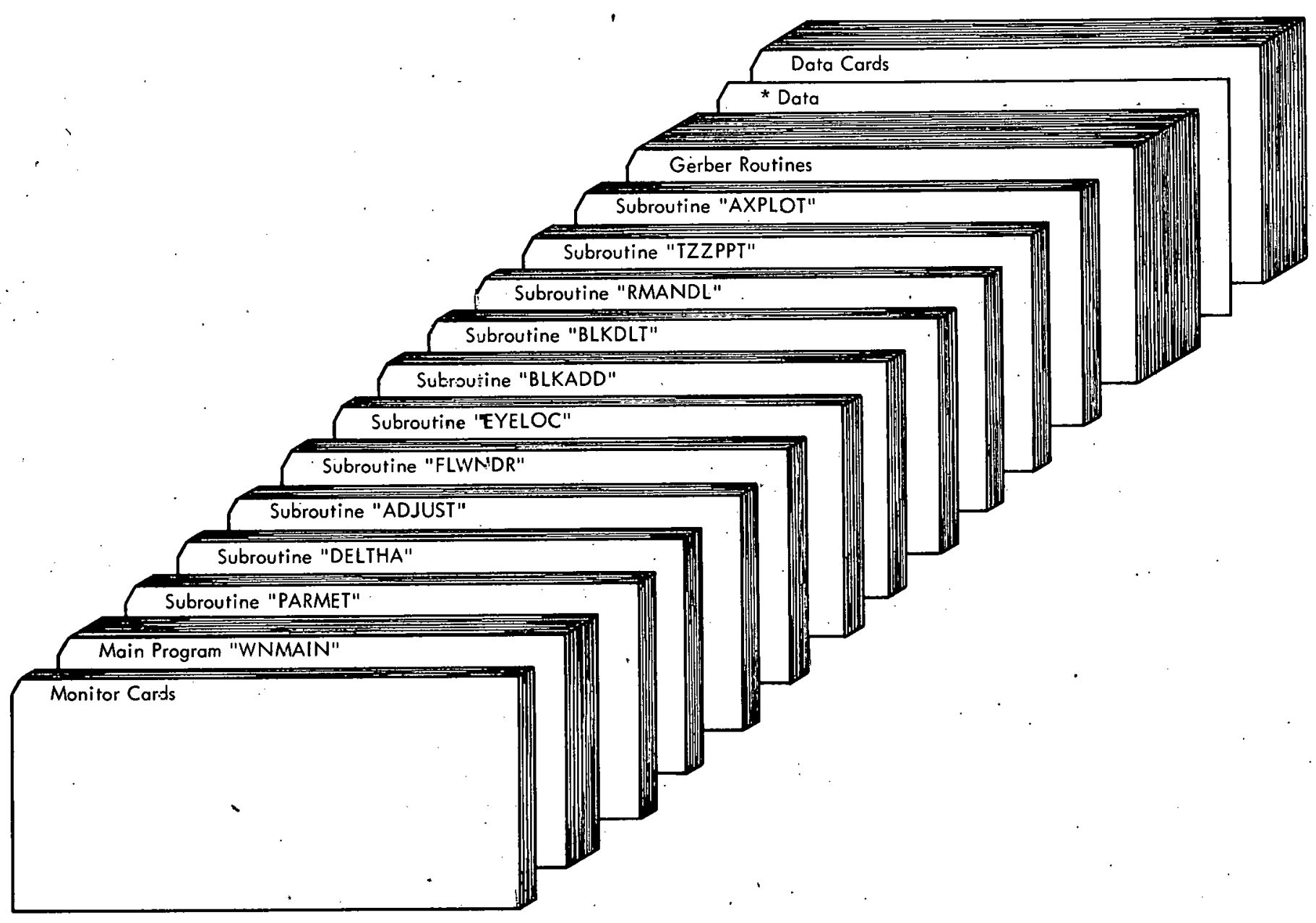

Figure A-2. 'PROGRAM DECK ARRANGEMENT. 
desired tolerance. If the point on the surface corresponding to a payout-eye position is a defining point of the surface, the average slope is computed and used in locating the eye. It is in this routine that the surface and eye positions are printed as output. The first argument of FLWNDR is the geodesic number. The next four arguments are the cylindrical coordinates and the $A$ angle of the eye at the finish of the previous geodesic (if $\mathrm{I}>1$ ). (This information can be utilized in transitioning from one geodesic to another.) The fifth argument is the vector length at the last computed eye position. The final argument is the tolerance desired, spiral to geodesic.

\section{Subroutine EYELOC}

This routine is called by FLWNDR to determine the position of the payout eye corresponding to a wrap point on the surface. The payout eye is located so that the eye clears the mandrel by the desired amount. It is also in the routine that the $A$ angle of the eye is computed. The first argument of EYELOC is the geodesic number; the next three arguments are the cylindrical coordinates of the point on the surface $(r, z, \theta)$; the fifth argument is the last used vector length; the next argument is a flag indicating increasing or decreasing $Z$ (going up or down part); the next two arguments are the average slope, $k_{n}$, and $\sqrt{1+k_{n}{ }^{2}}$ for that slope; and the ninth argument is the theta coordinate of the previous eye position. The routine returns $w$ ith the next four arguments which are the coordinates and the A angle of the payout eye. The final argument is the length of filament laid on the surface in making the present motion.

\section{Subroutine BLKADD}

This routine is called when a large $\Delta \theta$ of the eye is encountered. Additional eye positions are computed for $\Delta \theta$ (eye) in increments of DBA, which is currently set in this routine at 18 degrees. The first argument of BLKADD is the geodesic number; the next five arguments are the surface coordinates $(r, z, \theta)$, the surface slope, and the $\theta$ coordinate of the eye at the beginning of the motion; the next five arguments are the surface coordinates $(r, z, \theta)$, the surface slope, and the $\theta$ coordinate at the end of the motion; the twelfth argument is the length of filament fed from the eye during the motion, and the thirteenth is the length of filament laid on the surface. The final argument is a flag indicating increasing or decreasing $Z$ (going up or down part).

\section{Subroutine BLKDLT}

This routine is called by subroutine FLWNDR when all of the eye positions for a geodesic have been computed. The function of the routine is to eliminate eye points which are too closely spaced. A normalized five-dimensional motion vector is constructed. The eye positions, as shown on the output listing, are examined and points eliminated until the resulting motion is greater than the established minimum. The remaining points are written on magnetic tape in APT format as GO TO points. The single argument of this routine is the number of computed eye positions for the geodesic. 


\section{Subroutine RMANDL}

This routine determines the mandrel radius for a given $Z$ coordinate. This radius is used to compute eye clearance. If $Z$ is less than $z$, or greater than $z_{m}$, the appropriate shaft radius is used. The first argument is the $Z$ coordinate and the routine returns with the second argument, the radius of the mandrel.

\section{Subroutine TZZPPT}

This is the routine used in making the $Z-\theta$ and $R-Z$ plots. The first two arguments are the coordinates of the origin for the plots. The routine produces two plots each having their origin at $(X O, Y O)$. The third argument is the scale for the $Z$ axis of $Z-\theta$ plot and the fourth argument is the length for the theta axis. The fifth argument of TZZPPT is the scale for the $R-Z$ plot.

\section{Subroutine AXPLOT}

This routine, called by TZZPPT, is an axis generator. Its purpose is to draw and and label the axes for a plot.

\section{EXAMPLE OF PROGRAM USAGE}

As Example 1, two geodesics are computed for the mandrel shown in Figure 14. This mandrel is basically a cylinder joined on each end by cones having considerably different slopes. The ends of the mandrel are flat plates. Twenty-one points were used in defining the contour of the surface as shown in Figure A-3. The program input is presented in Figure A-4. The program output for this example is outlined in Table A-1. 


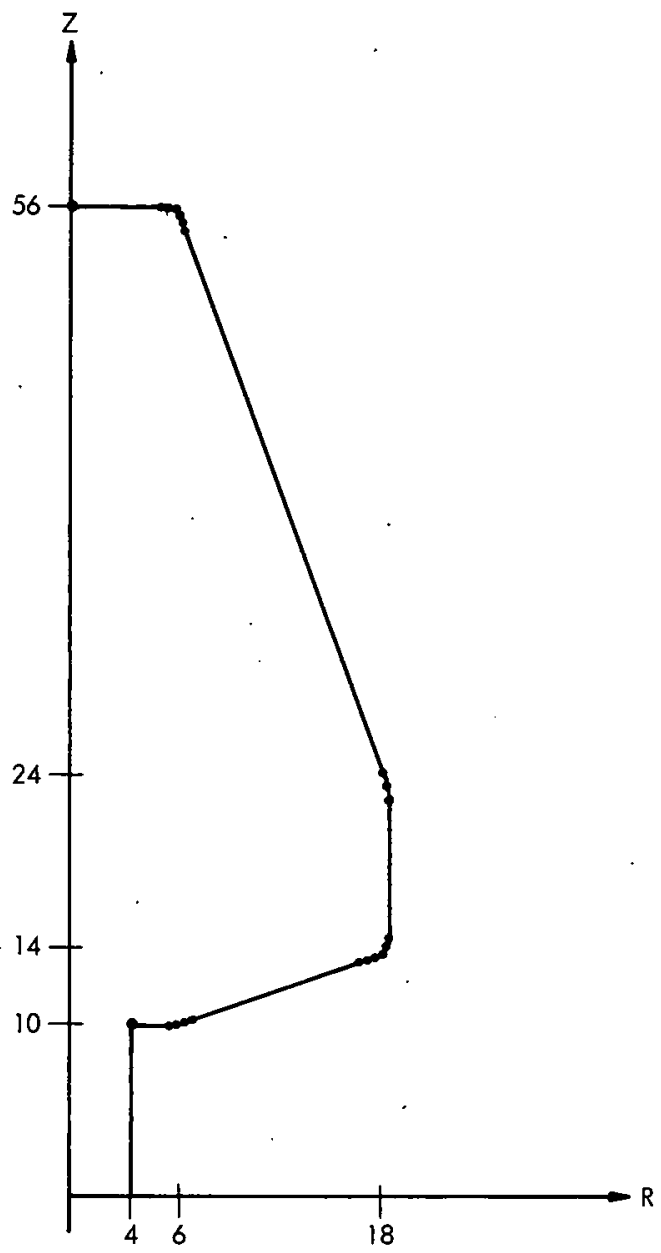

Figure A-3. CONTOUR OF SURFACE USED IN EXAMPLE. 


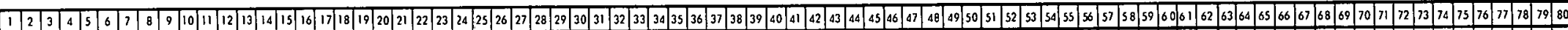

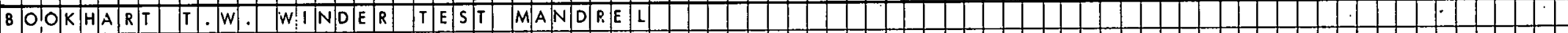

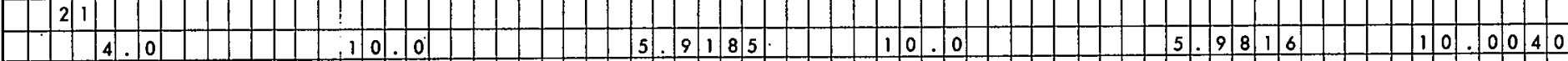

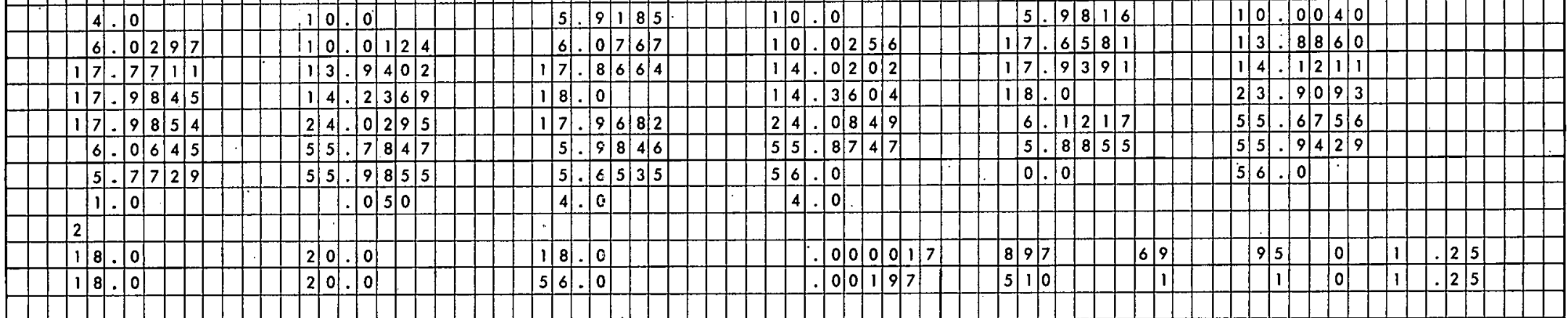

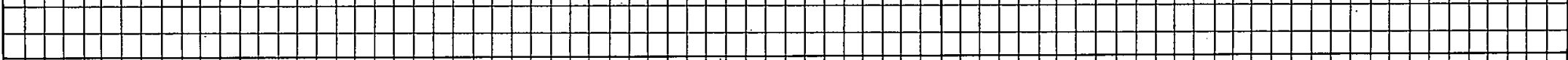

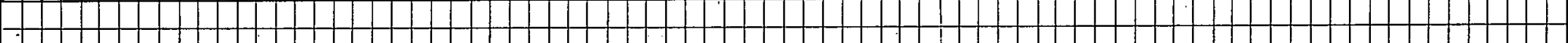

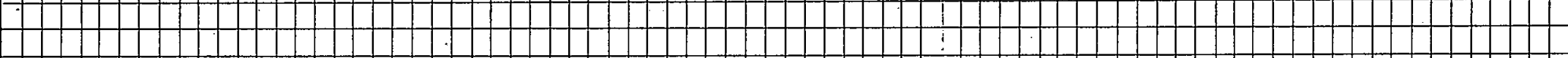

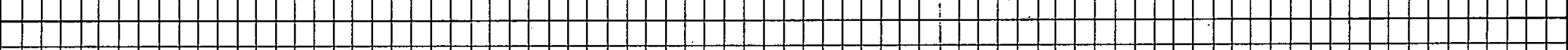

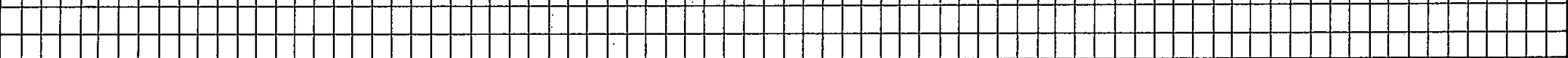

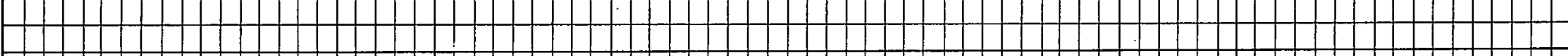
\begin{tabular}{|l|l|}
\hline \\
\hline
\end{tabular} 
Table A-1

\section{PRINTOUT FCR EXAMPLE}

\begin{tabular}{|c|c|c|c|c|c|c|c|c|c|c|c|c|}
\hline & $\begin{array}{l}\text { HEL IX } \\
\text { ANGLEE }\end{array}$ & $R^{A T}$ & POIN T & $\begin{array}{c}\text { TCTAL } \\
\text { RCTATICN }\end{array}$ & $\begin{array}{l}\text { DIST GRT } \\
\text { FACTCR }\end{array}$ & $\begin{array}{l}\text { FILNNT } \\
\text { LENGTH }\end{array}$ & $\begin{array}{l}\text { NO. OF } \\
\text { CIRCUITS }\end{array}$ & $\begin{array}{c}\text { CIRC PER } \\
\text { PATTERV }\end{array}$ & $\begin{array}{l}\text { REV PER } \\
\text { PATTEZN }\end{array}$ & $\begin{array}{l}\text { ADVANC,E } \\
\text { PER II }\end{array}$ & $\begin{array}{c}\text { WRAP } \\
\text { TOLERNCE }\end{array}$ & $\begin{array}{c}\text { CLEDR- } \\
\text { ANCE }\end{array}$ \\
\hline & 18.03 & $18 . \mathrm{ELCL}$ & $2 \mathrm{C} \cdot[\mathrm{C}[\mathrm{C}]$ & 495.66 & ] & 145.50 & 897 & 69 & 95 & D. nogec2 & Q. 0.5[ & (1.00. \\
\hline
\end{tabular}

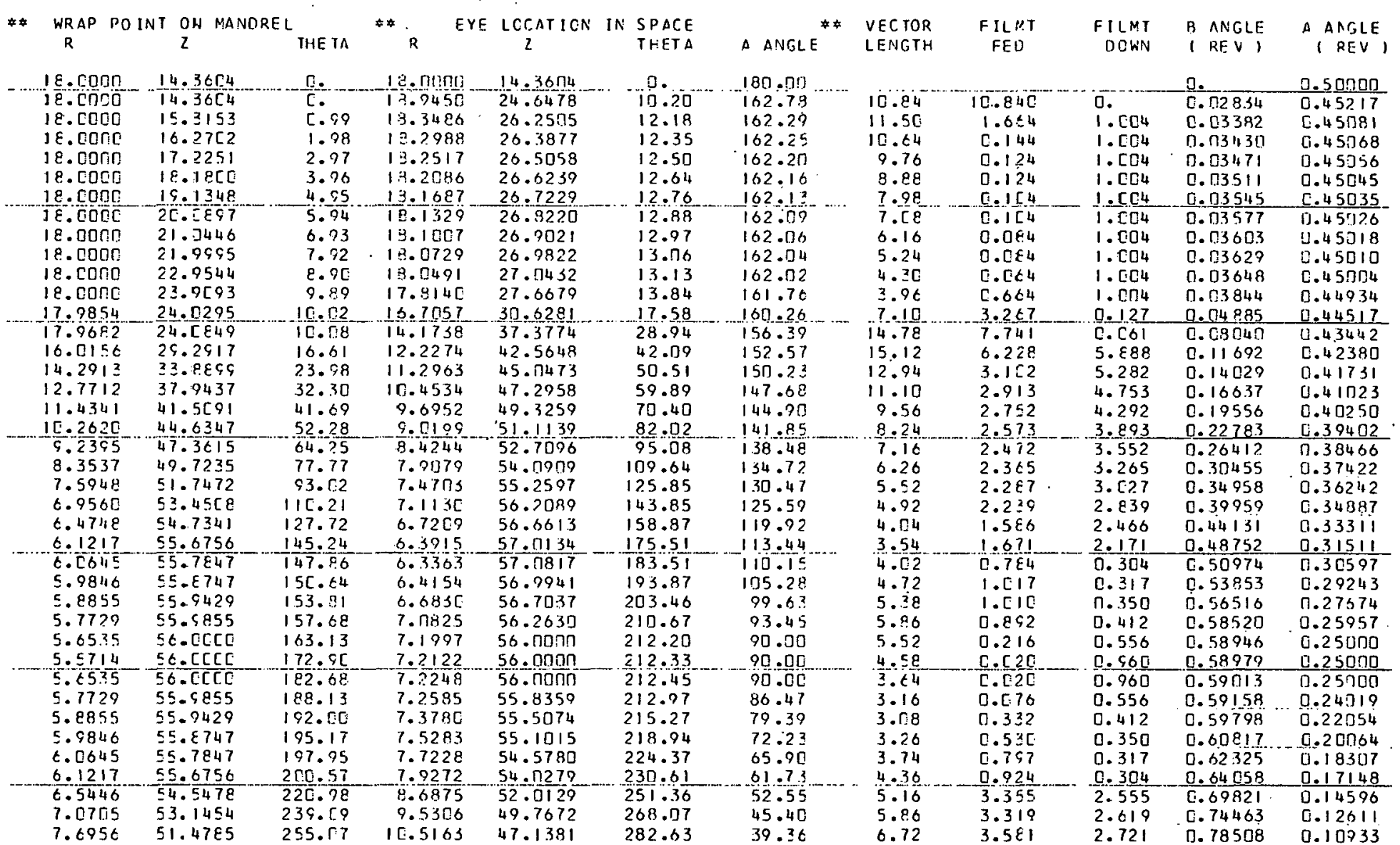


Table A-I (Continued)

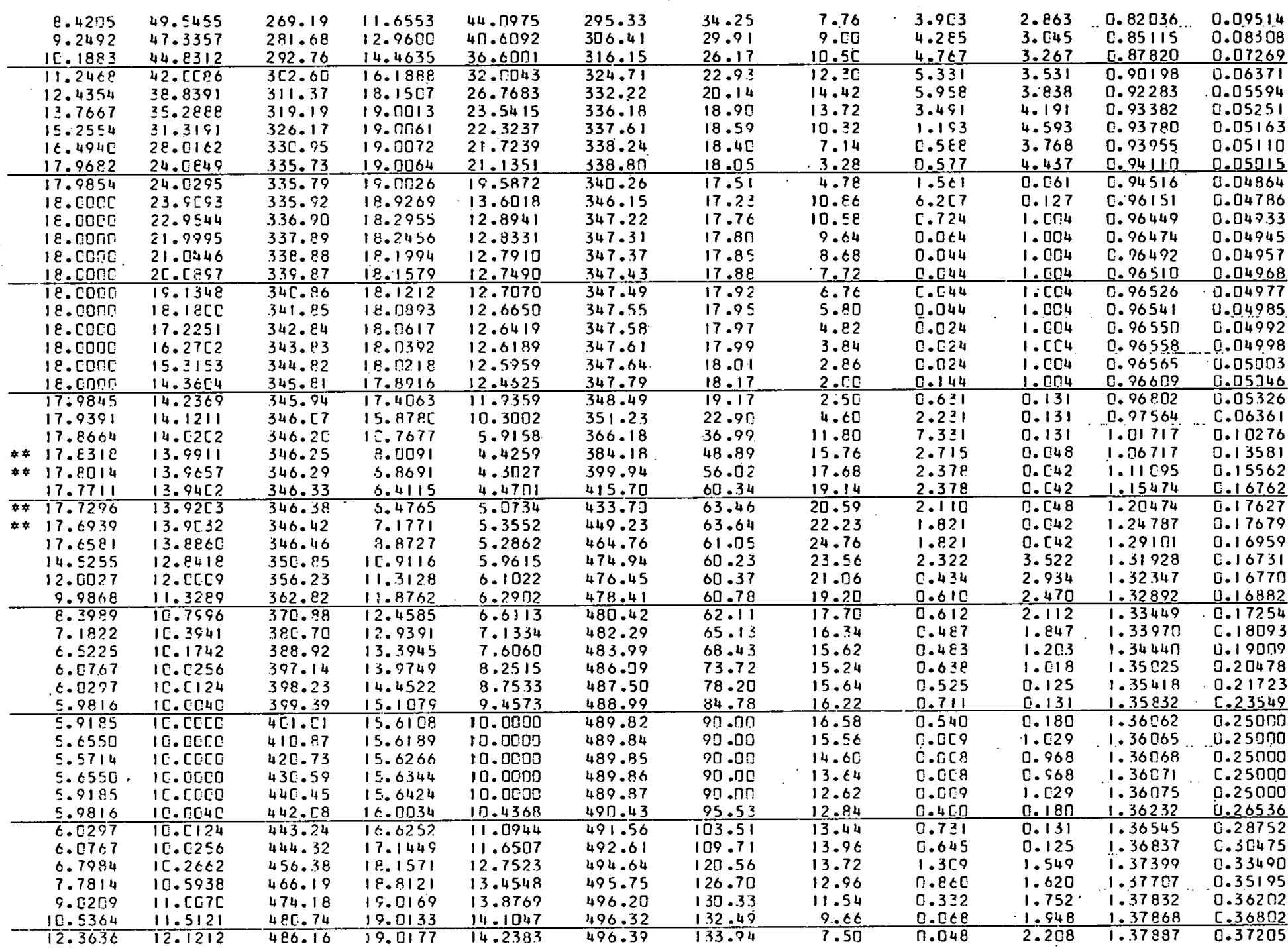


Table A-1 (Continued)

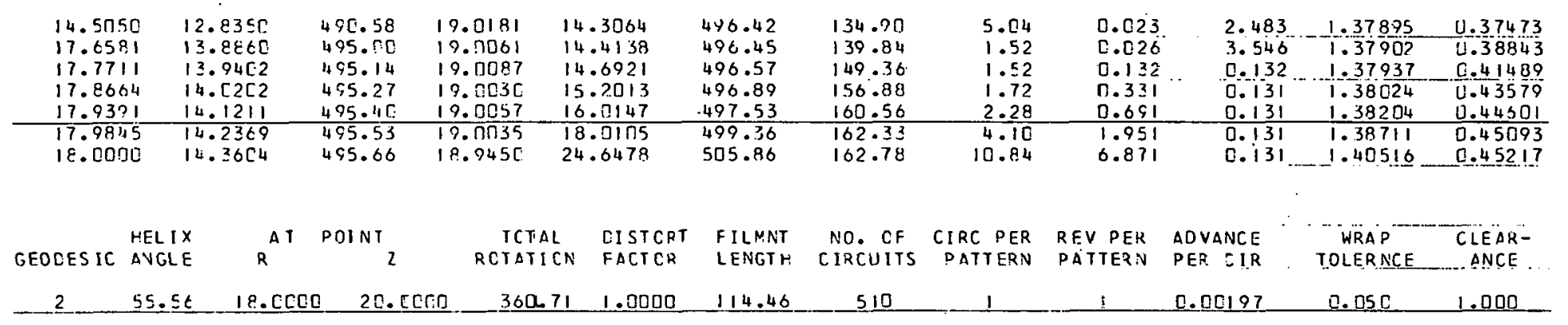

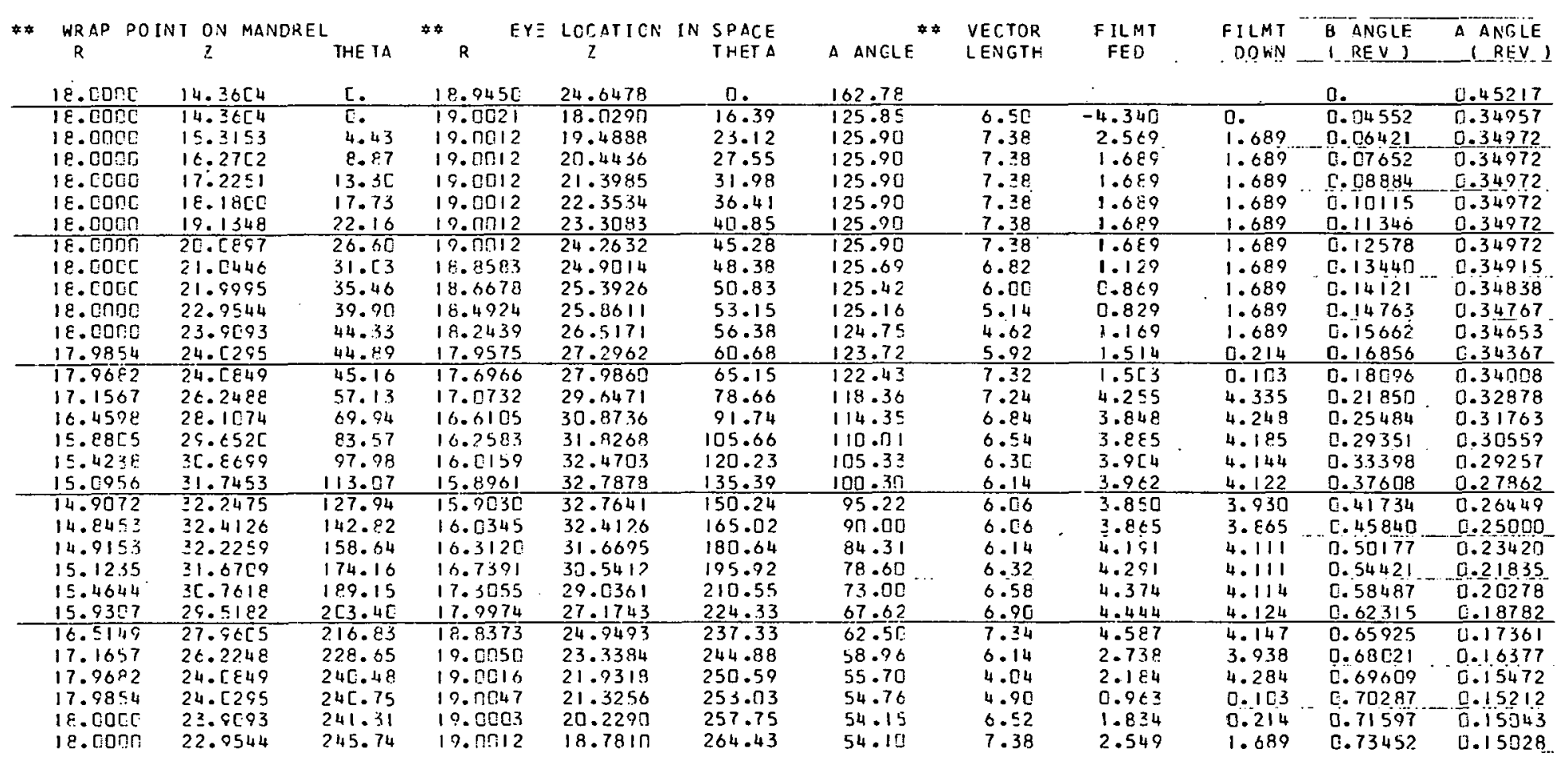


Table A-1 (Continued)

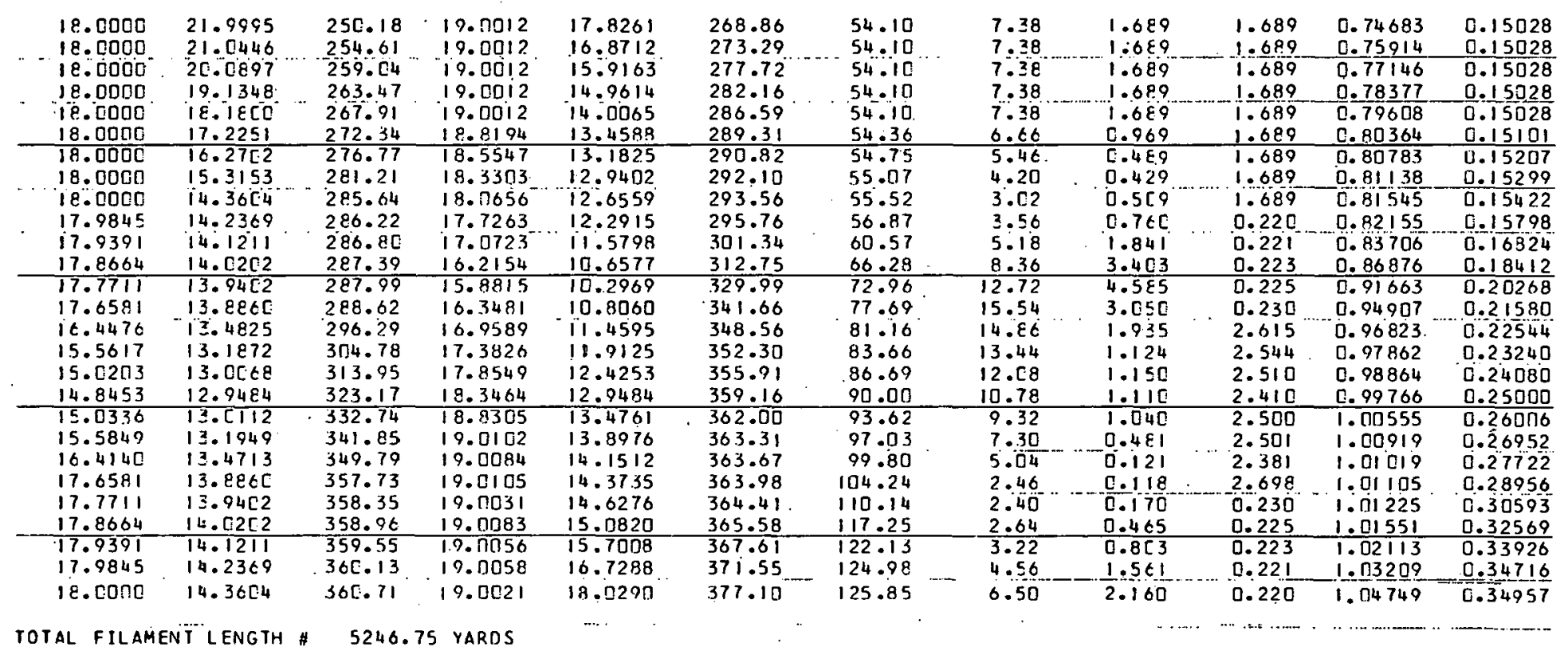

TOTAL FILAMENTILENGTH \# 5246.75 YARDS 


\section{PROGRAM LISTING}

\section{Main Program WNMAIN}

CWNIAIN MAIN PROGRAM FOR WINOER CALCULATIONS DIMENSION R( 1000$) ; 2(1000), A K(1000),, F(1000), X 1(1000), T$ ITLE $(12)$, IRO (100), ZO(100), ALPHAO(100), CCNS(IOD), W(100;, D(I00), THICK(IOO),

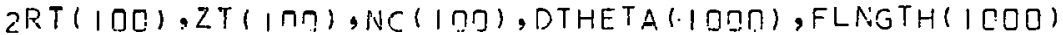
COMMON PI, R, Z, AK, F, XI, NOGFOD, RC, ZO, ALPHAC, CONS,W,D, IHICK, HC, RT,ZT, I SMAX, RMAX, ZMAX, THMAX, J, T I TLE, P I, DTHETA, FLINGTH, TSUM, FLSUM, NHIGH,

2 NLOW , DISTRT, ADVNCE, SHAFTI, SHAFT2

COMMON AA,PB,CC, DFL, DELRHO,NSTART

COMMON LLL, RHOMIN, FR, THIN

I0 READ INFUT TAPE 5, 4D5O, ( TITLE(K), K \#, 5 )

4050 FORMAT ( GAG)

C REAC NUMEFR OF DEFINING POINTS

READ INPUT TAPE 5,4 INC, M

- 40DD FORMAT ( I 4 )

C REAO IN COORDINATES OF DEFINING POINTS

READ INPUT TAPE $5,4010,(R(N), Z(N), N \# 1, M)$

40I0 FORMAT ( 6FI2.6)

C REAd CLeARANCE, TOLERANCE, AND SHAFT RADII

READ INPUT TAPE 5, 40I0, DEL, TOL, SHAFTI, SHAFT2

$C$ INITIALIZE EYE DIMENSIONS A, $B, C$

AA \#.5

$B B \# 6.5$

CC \#7.0

r. INTTIALIZE INCREMENT DELTA RHO

DELRHO \#.020

C INITIALIZE MINIMU:N VECTOR LENGTH

RHOMIN \#.5

PI $\# 3.1415927$

FLTOTL \# 0.0

C COMPUTE SECTION PARAMETERS

CALL PARMET

C P.EAD NIIMFFR QF GEODESICS

READ INPUT TAPE 5, 4000 , NÜGEUO

REWIND 8

C START OF LOCP FOR EACH GEODESIC TO EE WRAPPED DO 500 I \# I, NOGEOD DISTRT \# 1.0

C READ GEODESIC DEFINING INFORMATION READ INPUT TAPE 5, 4020 , RO(I), ZO(I), ALPHAO(I), ADVINCE, NC(I), I NCPERP, NREVPT, LA, IPLOT, ZSCALE

402 FORHAT ( $4 \mathrm{~F} 12.6 ., 3$ IS, 2 I $3, F 4.2)$ IF $(20(1), 12,12,27$

12 DO $15 N \# 2, M$

IF $(R O(I)-R(N), 25,25,15$

15 CONTINUE

WRITE OUTPUT TAPE $6,2050, I$, RO(I)

2050 FCRMAT $144 \mathrm{H} 3$ COULC NOT LOCATE INITIAL PCINT OF GEOLESIC, I3, I 25 H USING INITIAL RADIUS OF, F .3, I 3 , THIS ONE SKIPPED, GO TO 500

$20 N \# N+1$

25 NSTART \#NIF ( AK(NSTART), $30,35,30$

$30 Z O(I) \#$ ( RO(I) - R(NSTART), / AK(NSTART) + Z(NSTART) GO TO 37

35 ZOI $\$$ Z (NSTART)

37 CONTINUE 
C COMPUTE GEODESIC PATH ON THE SURFACE

CALL DELTHA $($ I I

NLOW \# NLOW

$\mathrm{NHIGH} \# \mathrm{NHIGH}$

C ARE THE NUMBER OF CIRCUITS PER PATTERN SPECIFIED

IF. I NCPERP, $150,150,110$

IIO RVN. \# TSUM / 360.0

FRACT \# RVN

NB \# NCPERP

NA \# NREVPT

IF ( LA ) 120, 120, 130

120 EPS \# .OחCOI

C COMPUTE NEW GEODESIC HAVING DESIRED NUMBER OF REVOLUTIONS PER CIRCUIT CALL ADJUST,$I$, NA, NE, FRACT, EPS, LL'

NLOW \# NLOW

$\mathrm{NHIGH}$ \# NHIGH

IF ( LL , 150, 150, 130

130 CONTINUE

RVN2 \# FLOATF(NA) / FLOATF(NB) + ADVNCE

DISTRT \# RVN2, RVN

- DO $140 \mathrm{~N} \#$ NLOW, NHIGH

DTHETA $(N)$ \# DTHETA $(N)$ * DISTRT

140 CONTINUE

TSUM \# TSUM * DISTRT

150 CONTINUE

C COMPUTE TURNAROUND PARALLELS

ZLOW \# ( CONS(I) - R(NLOW) ) / AK(NLOW) + Z(NLOW)

ZHIGH \#, CONSII) - R(NHIGH), $A K(N H I G H)+Z(N H I G H)$

WR ITE OUTPUT TAPE $6 ; 5000$

5000 FORMAT 1 12OHI HELIX AT POINT TOTAL DISTOR IT FILMNT NO. OF CIRC PER REV PER ADVANCE WRAP . CLEAR $2-1$ I2QH GEODESIC ANGLE R R 2 ROTATION FACTOR LE 3NGTH CIRCLITS PATTERN PATTERN PER CIR TOLERNCE ANCE, WRITE OUTPUT TAPE 6, 50IO, I, ALPHAC(I), RO(I), ZO(I), TSUM, I DISTRT, FLSUM, NC(1), NCPERP, NREVPT, ADVNCE, TOL, DEL

5010 FORMAT I IHO, I 4,FIO.2,2FIO.4,FIO.2,F8.4,F9.2,2I8,I9,FI2.5,2FIO.3)

$C$ COMPUTE WINDER EYE COOREINATES FOR GEODESIS ON THF SIIPFACE CALL FLWHUR I I, RPI, ZPI, TPI, AANGLI, RHOI, TOL, FLTOTL \# FLTOTL + FLSUM * FLOATF ( NC(I) )

C PLOT WANTED IF ( IPLOT , $500,500,170$

C CALL PLOTTING ROUTINE

170 CALL TZZPPT ( 0.0, O. . ZSCALE, 10.0, ZSCALE,

5OD CONTINUE

C END LOOP

FLTOT. \#FLTOTL / 36.0

WRITE OUTPUTT TAPE 6,5050, FLTOT

5050 FORMAT ( 24HOTOTAL FILAMENT LENGTH \#, FID.2, 6H YARDS ) GO TO 10

END

* LABEL

\section{Subroutine PARMET}

CPARMET

SUBROUTTNE PARMET

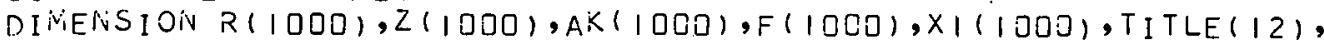
IRO ( 100$), Z O(100)$, ALPHAO $(100)$, CONS(100), W(100;,D(100), THICK $(100)$,

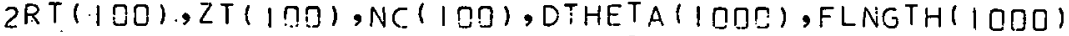

CONIMON $\mathrm{NI}, R, Z, A K, F, X I$, NOGEOD,RO, ZO, ALPHAC, CONS, W, D, THICK,NC,RT, ZT, 
I SMAX, RMAX, ZMAX, THMAX, U, T I TLE, P I , DTHETA, FLNGTH, TSUM, FLSUM, NHI GH,

2 NLOW, DISTRT, ADVNCE, SHAFTI, SHAFT2

$X 111)$ \# 0.0

$M M \# M-1$

RMAX \# R(1)

DO $1200 N \# 1, M M$

IF ( ABSF $(Z(N)-Z(N+1))-.0001) 1010,1010,1040$

1010 IF $(R(N+1)-R(N), 1020,1020,1030$

$1020 A K(N) \#-(1.0 E 20)$

GO TO 1035

1030 AK $(N)$ \# 1.0 E 20

$1035 \mathrm{~F}(\mathrm{~N}) \# 1.0 \mathrm{E} 20$

$X_{1}(N+1) \# X_{1}(N)+A E S F(R(N+1)-R(N))$

GO TO 1200

1040 AK(N) \# $(R(N+1)-R(N)),(Z(N+1)-Z(N))$

IF $(A B S F(A K(N),-.0001,1050,1050,1100$

1050 AK(N) \# 0.0

$1100 F(N)$ \# SORTF( $1.0+A K(N) * * 2)$

$X|(N+1) * X|(N)+(Z(N+1)-Z(N)) * F(N)$

1200 RMAX \# MAXIF ( R $(N+1)$, RMAX)

$Z M A X \# Z(M)$

RETURN

END

* LABEL

Subroutine DELTHA

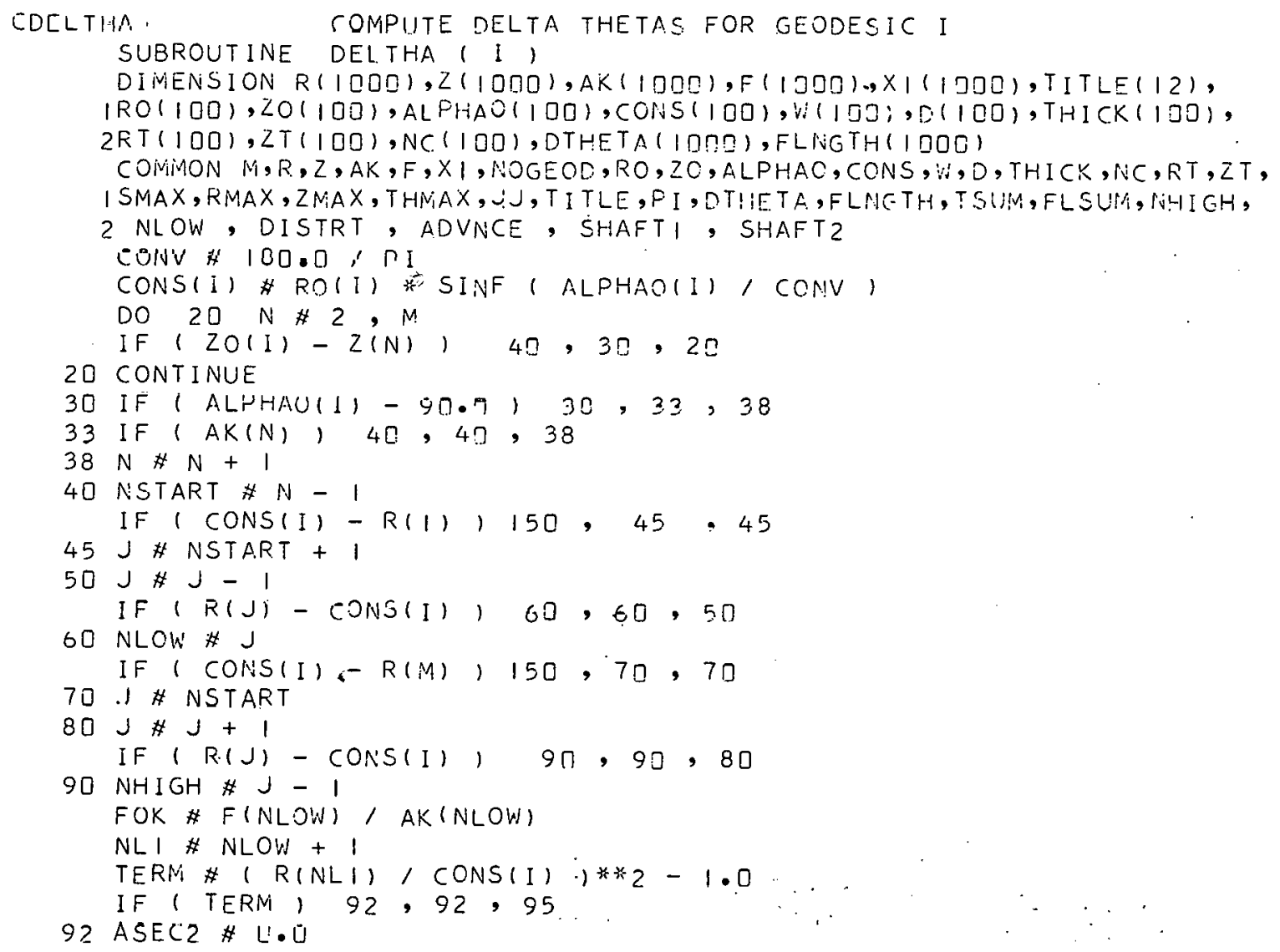




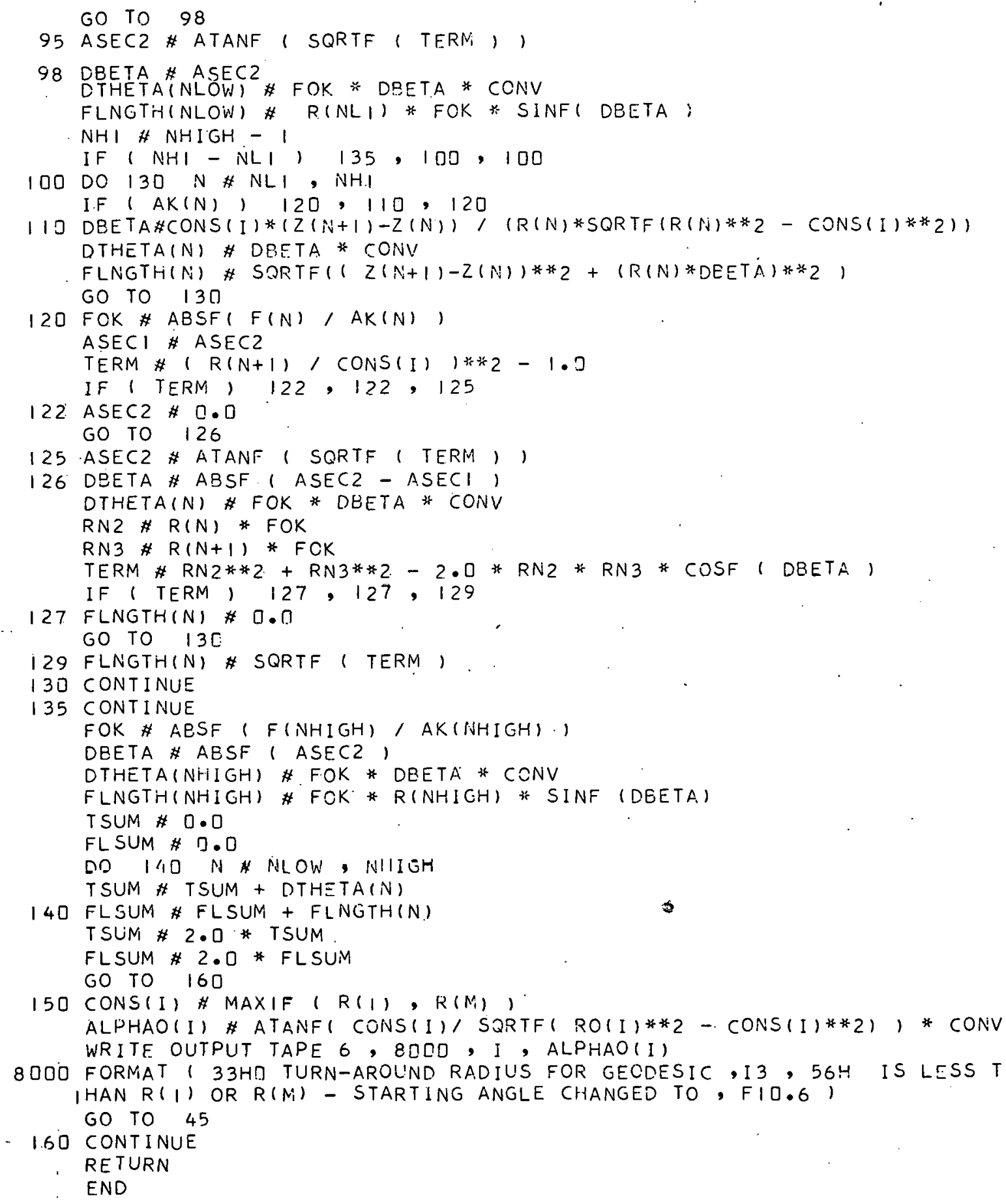

\section{Subroutine ADJUST}

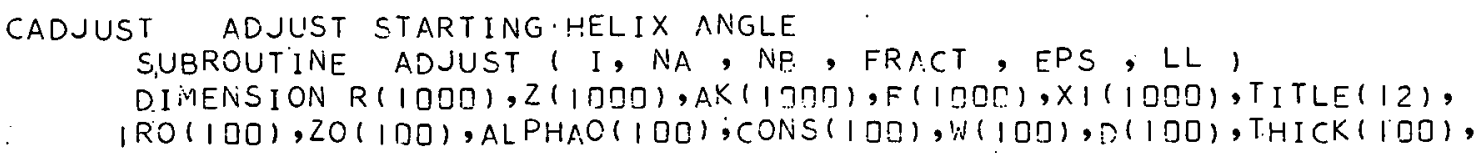


2RT ( IOO), ZT ( IOO), NC ( IDO), DTHETA ( I CCO ), FLNGTH ( I QDO )

COMNION $M, R, Z, A K, F, X I$, NOGEOD,RO,ZO, ALPHAO, CONS, 'W, D, THICK, NC, RT, ZT,

I SMAX, RMAX, ZMAX, THMAX, J, T I TLE, P I, DTHE TA, FLNGTH, TSUM, FLSUM, NHI GH,

2 NLOW, DISTRT, ADVNCE, SHAFTI, SHAFT2

CONV \#180.0/PI

I TER \# 0

AZERO \# ALPHAO(I)

RZERO \# RO(I)

ZZERO \#ZO(I)

5 \# CONS(I)

IF ( ALPHAO(I) - 89.0) $30,30,20$

20 RO(I) \# RMAX

ALPHAO(I): \# ATANF( CONS(I), SORTF( RO(I)**2-CONS(I)**2i, *CONV DO $22 N \# 2, M$

IF $(R O(I)-R(N), 24,24,22$

22 CONTINUE

$24 \mathrm{ZO}(\mathrm{I}) \# Z(N)$

30 FRCH FRACT

RV \# FLOATF( NA ) / FLOATF ( NE) + NDVNCE

AAZERO \# ALPHAO(I)

40 CONTINUE.

DELA\# RV - FRC

IF ( ABSF ( DELA) - EPS , 110, 110, 50

50 DTDA \# 0.0

CSQ \# CONS(1)**2

$R \operatorname{COS}$ \#RO(I) * COSF ( ALPHAO(I) / CONV)

$\mathrm{NLI}$ \# NLOW + 1

$\mathrm{NHI} \# \mathrm{NHIGH}-1$

SQ2 \# I.D, SQRTF (R(NLI)*\#2-CSQ)

DTDA \# DTDA - F(NLOW) * RCOS * SQ2 / AK(NLOW)

IT $(\mathrm{NHH} \Rightarrow \mathrm{NLI}, 85,55,55$

55 DO 80 N \# NLI, NHil

IF ( AK $(N), 60,70,60$

60 SQ1 \# SQ2

SQ2 \#1.0 / SQRTF ( R $(N+1) * * 2-C S Q)$

DTDA \# DTDA + F(N) * RCOS *1-SQ2 + SQ1, / A.K (N) GO TO 80

70 DTDA \# DTDA + RCOS *R(N) * $(Z(N+1)-Z(N)) *(5 Q 2 * * 3)$

YU CUNIIINUE

85 DTDA \# DTDA + F(NHIGH) * RCOS * SQ2 / AK(NHIGH)

DTDA \# 2.0 * DTDA

. IF ( AESF! DTDA , - .01).140,140;90

90 DALPHA \# DELA* 360.0 / DTDA

ALPHAO (I) \# ALHHAO)(I) + DALPHA

IF ( ITER - ID , IOC, 150, 150

1 ITO ITER \# ITER + I

CONS (I) \# RO(I) * SINF ( ALPHAO I ) / CONV )

CALL DELTHA 11 ,

NLOW \# NLOW

$\mathrm{NHIGH} \# \mathrm{NHIGH}$

FRC \# TSUM / 360.0

GO TO 40

110 DALPHA \# ALPHAO(I) - AAZERO

IF ( AR.SF ( DALPHA) - 5.0, 120, 130, 130

120 LL \# 0

GO TO 170

130 WRITE OUTPUT TAPE 6, I QOD, DALPHA

1000 FORMAT 1 2OHO CHANGE IN ALPHA, , FI0.6, 43H, TOO GREAT - GEOD IESIC DISTORTED INSTEAD ।

GO TO 160

140 WRITE. OUTPUT TAPE $6,1 \Pi I \Pi$, DTDA

IDIO FORMAI $122 \mathrm{HO} 0$ THETA, D ALPHA \#, F9.6,7IH, LARGE CHANGE IN 


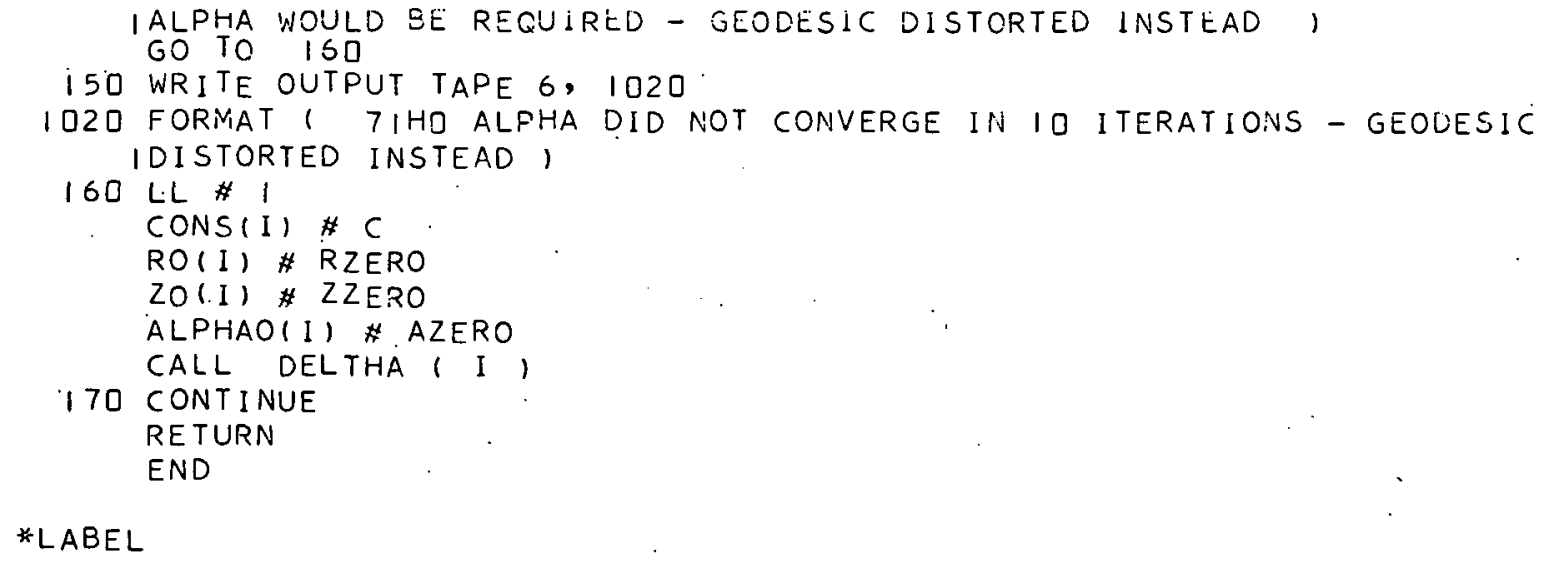

*LABEL

\section{Subroutine FLWNDR}

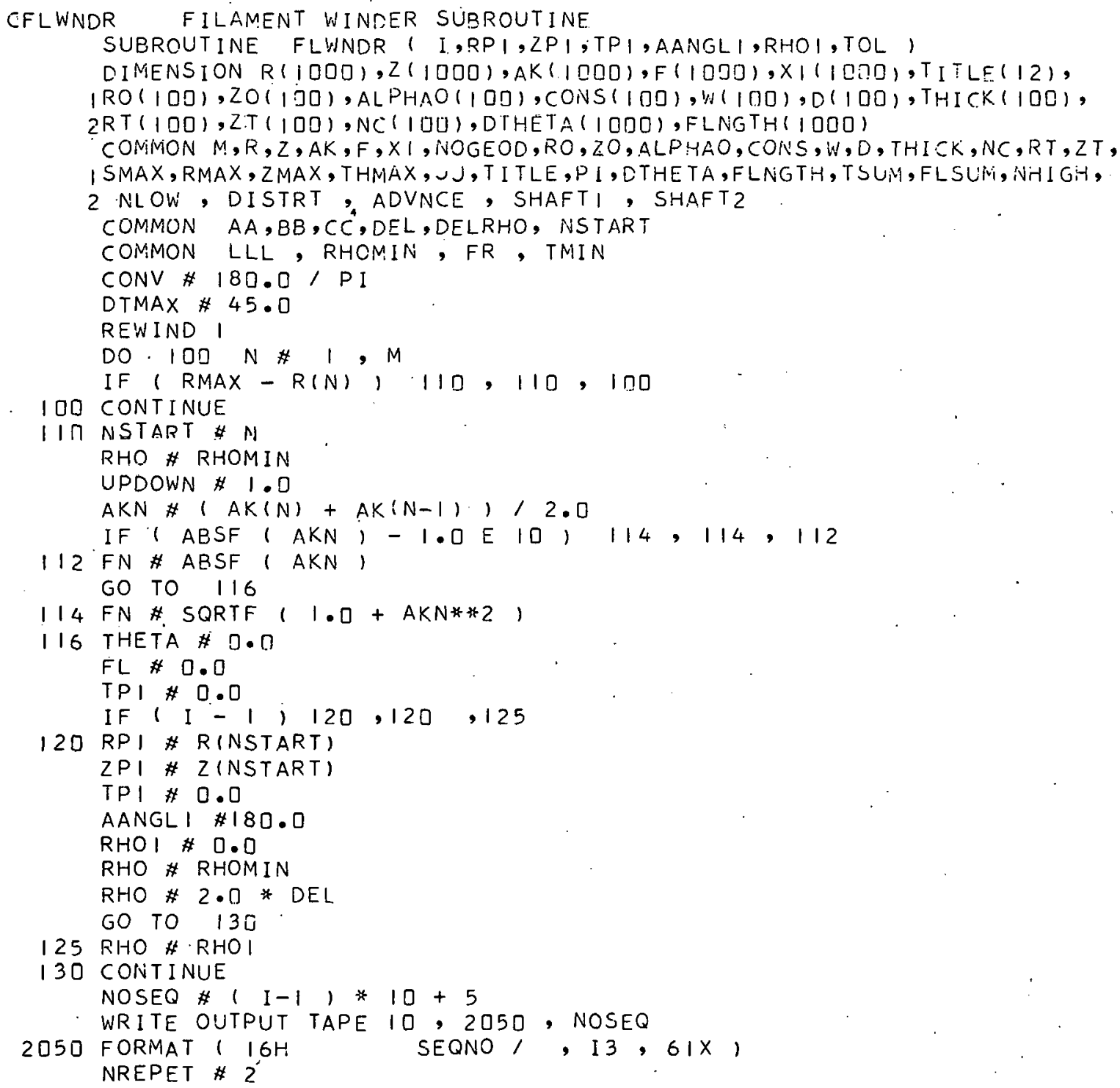




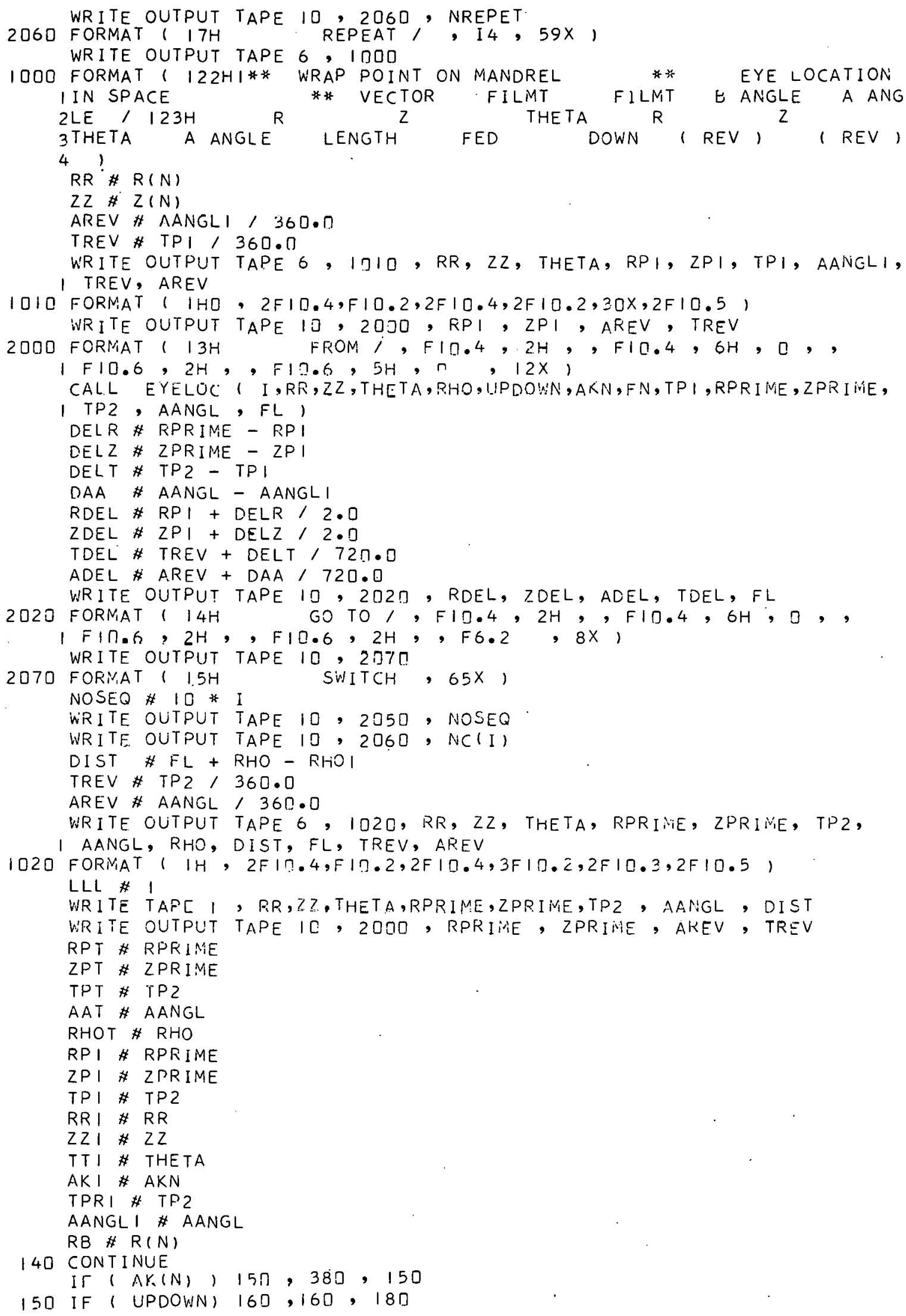




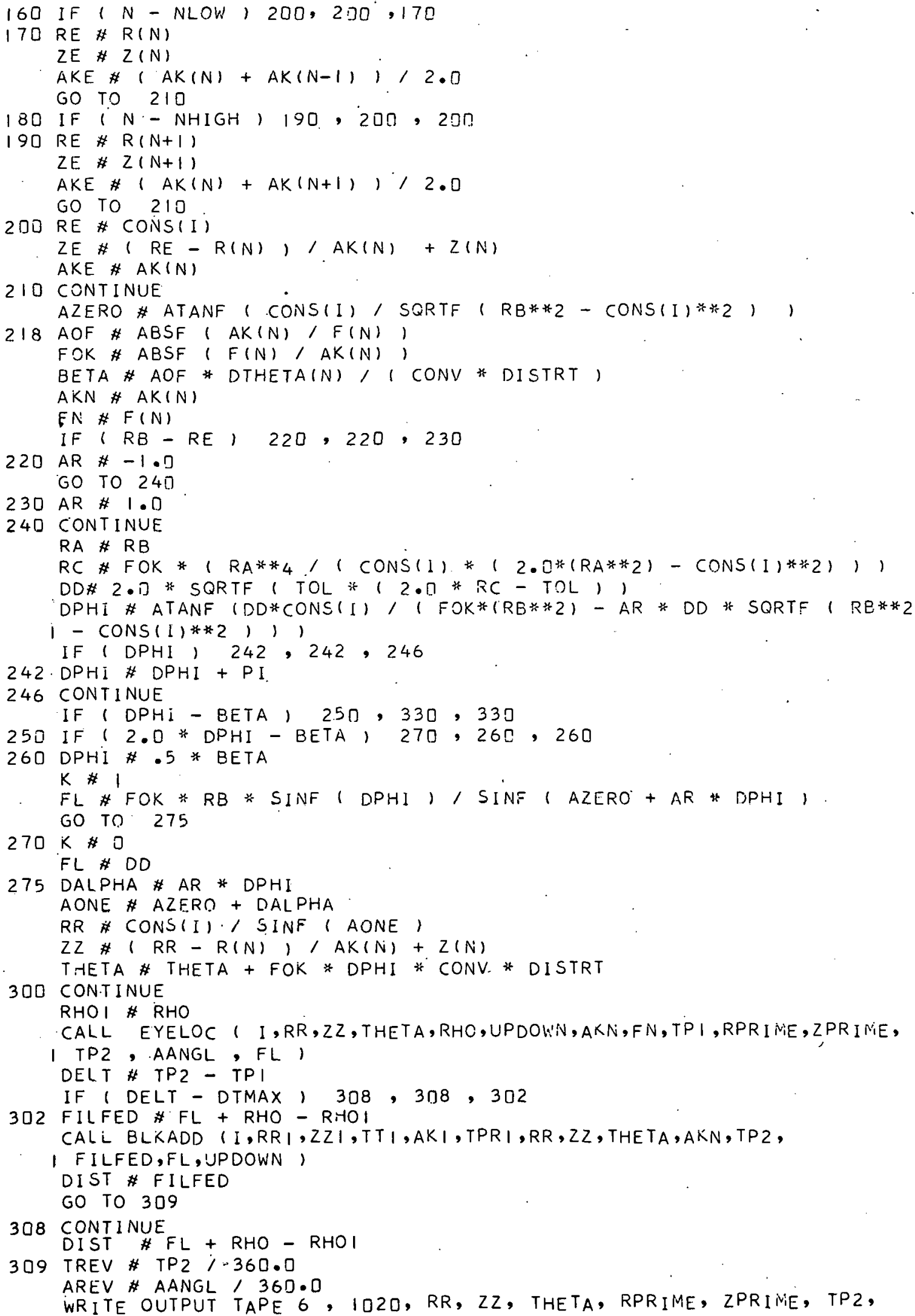




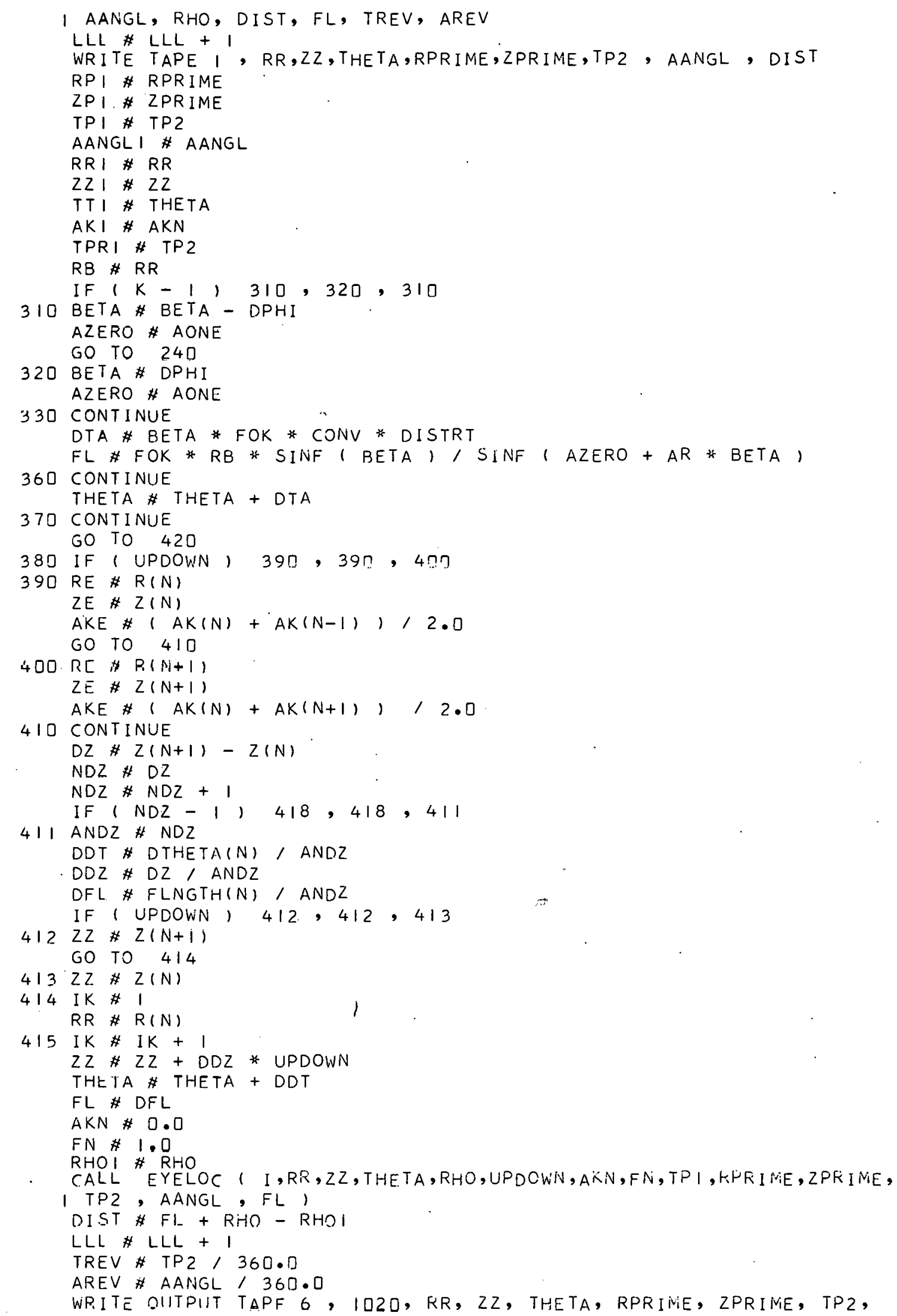




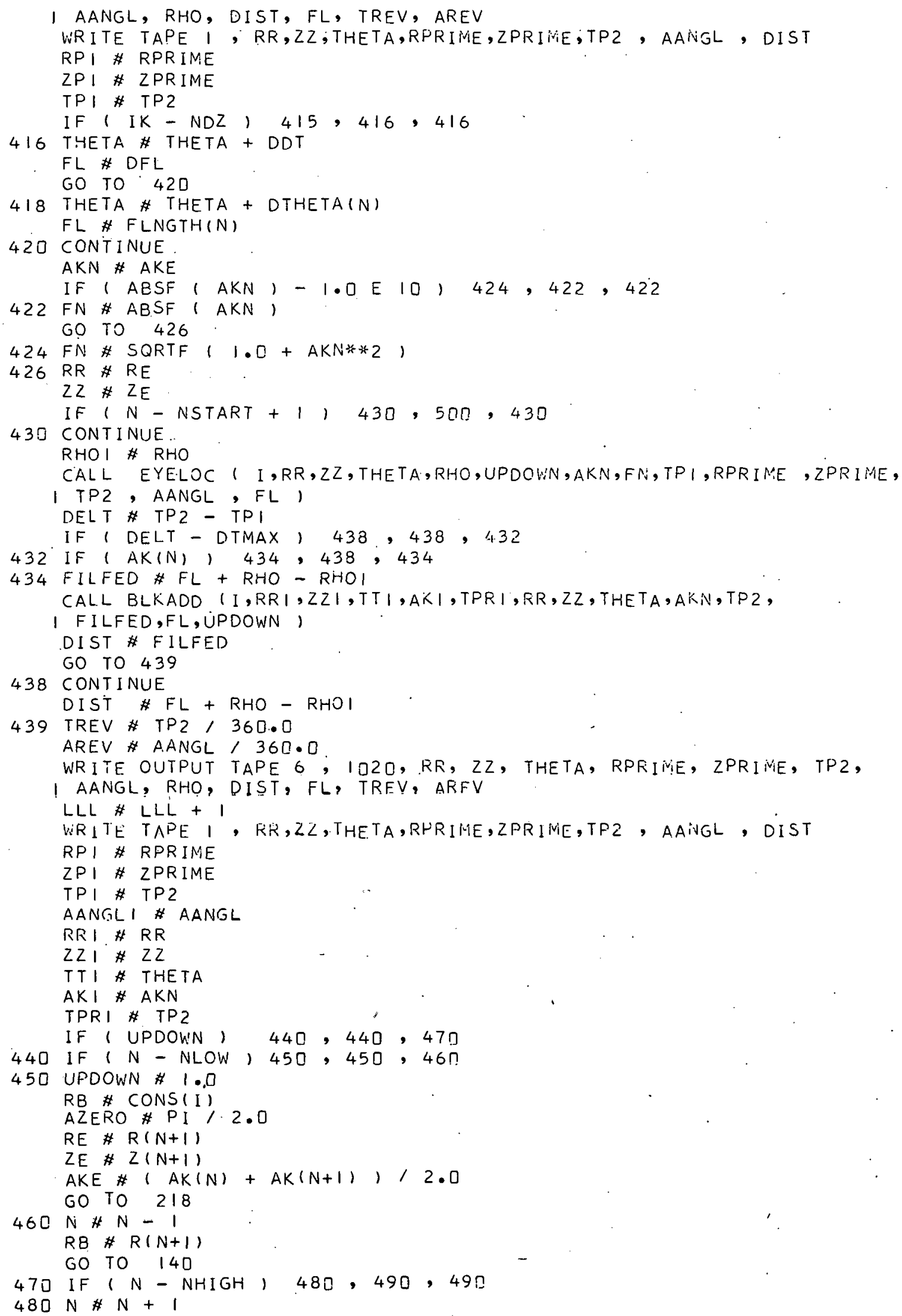




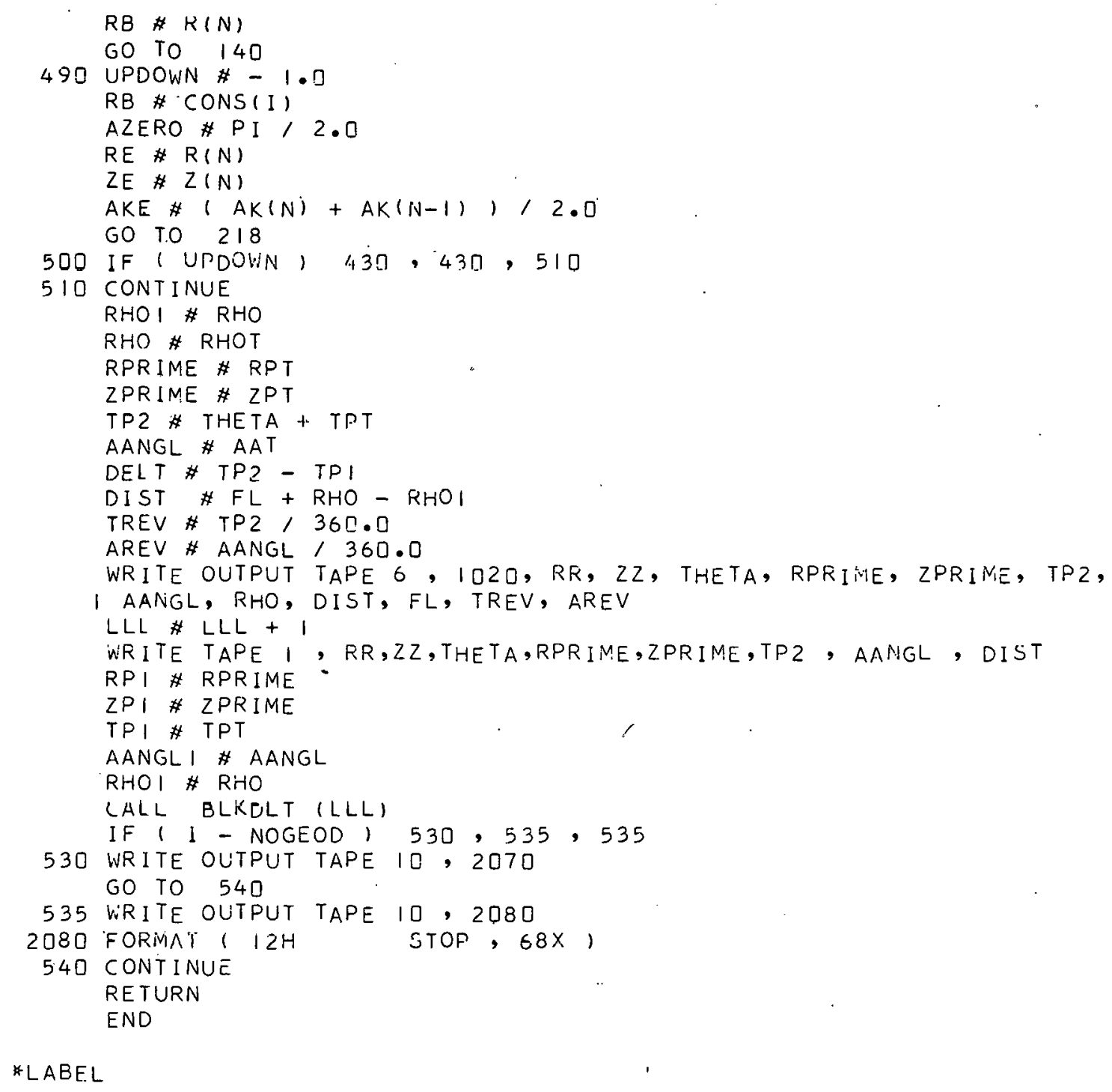

\section{Subroutine EYẼLOC}

CEYELOC DETERMINE WINDER EYE LOCATION WHICH CLEARS MANDREL

SUBROUTINE EYELOC I I, RR,ZZ, THETA, RHO, UPDOWN, AKN, FN,TPI,

I RPRIME, ZPRIME,TP2, AANGL, FL )

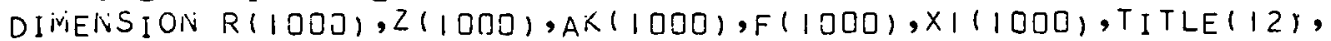

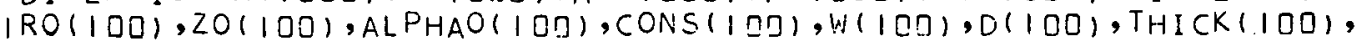

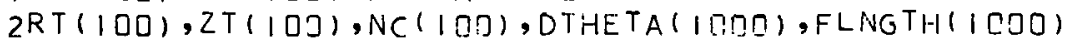

CCNIVION M, R, Z, AK, F, XI, NOGEOD, RO, ZO, ALPHAO;CONS, W, D, THICK, NC, RT, ZT, I SMAX, RMAX, ZMAX, THMAX, J, TI TLE, PI , DTHETA, FLNGTH, TSUM, FLSUN, NHI GH,

2 NLOW, DISTRT, ADVNCE, SHAFTI, SHAFT2

COMIION AA,RB, CC,DEL,DELRHO,NSTART

COMMON LLL, RHCVIN, FR, THIN

CONV \# $180.0 / P I$

RHOI \# RHO

SINA \# CONS(I) / RR

COSA * SQRTF ( RR**2 - CONS(I)*\#2) / RR

$K \# 0$ 


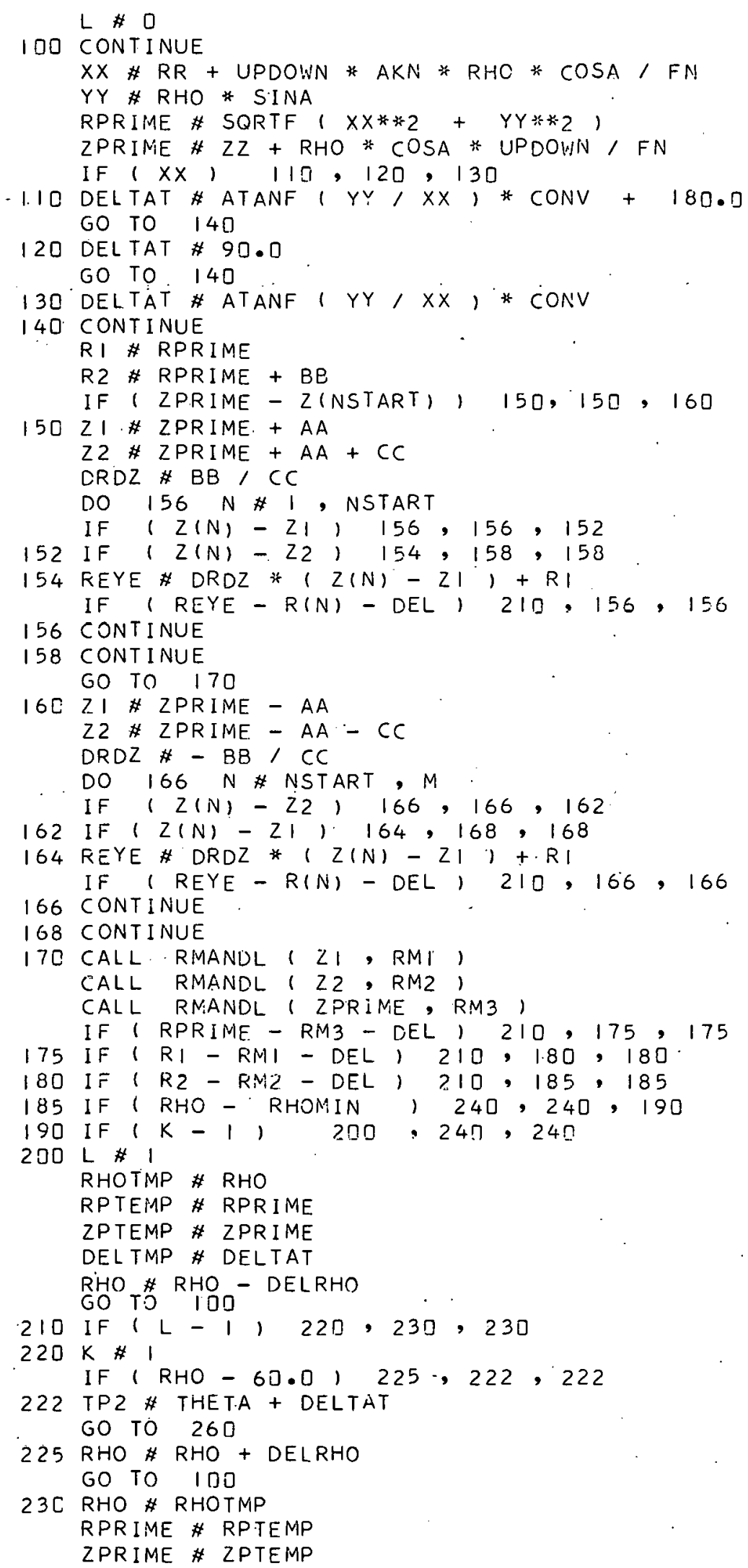




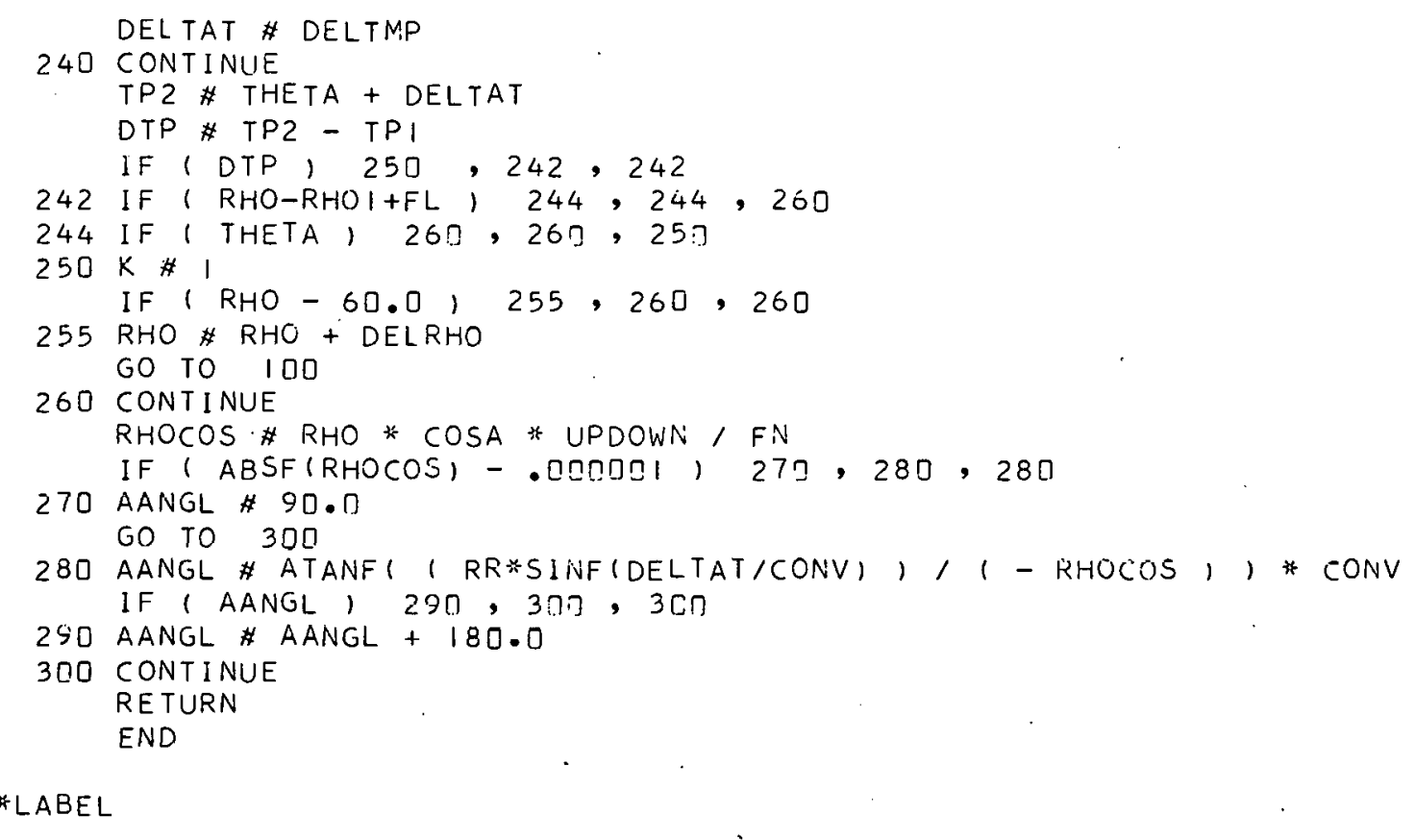

\section{Subroutine BLKADD}

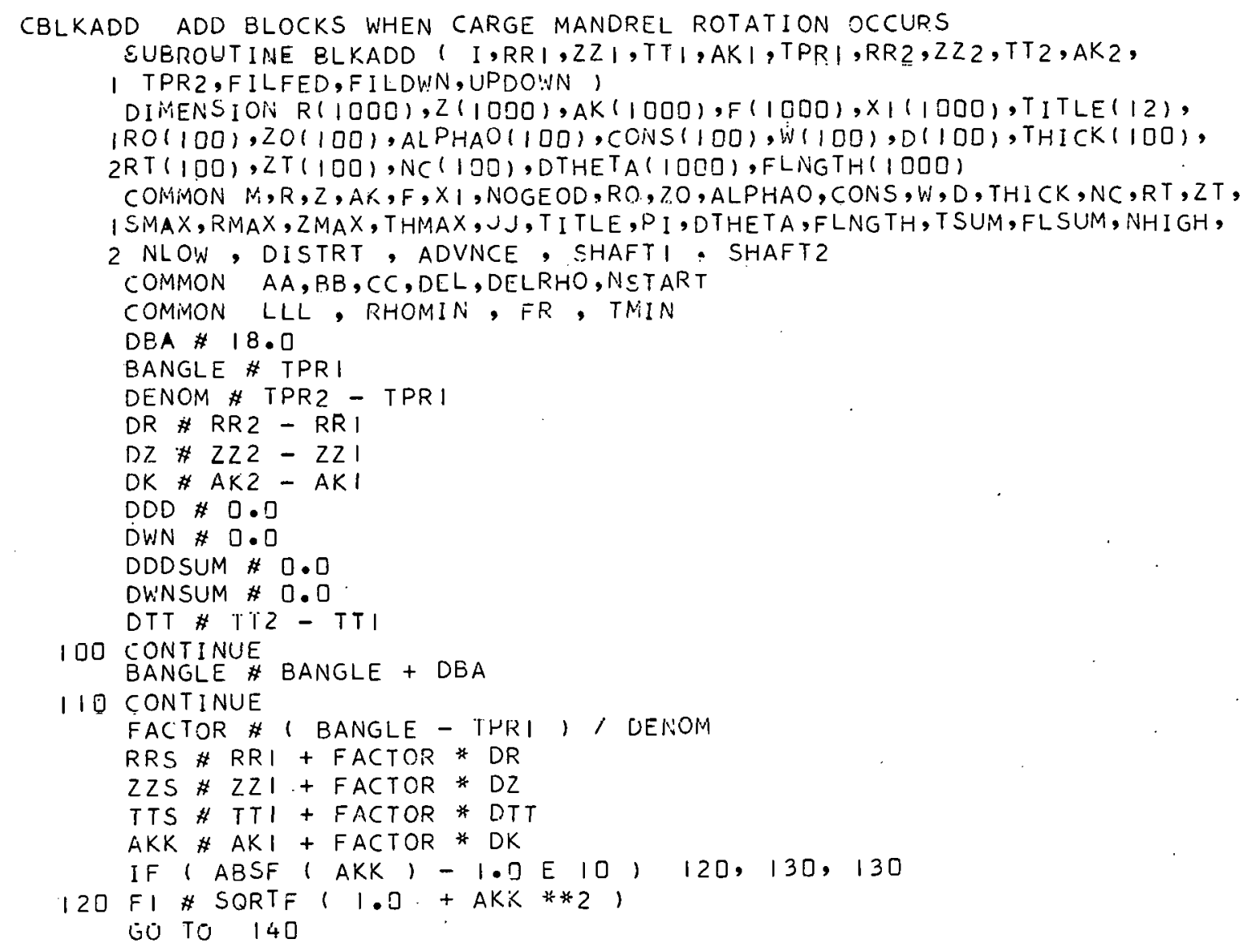




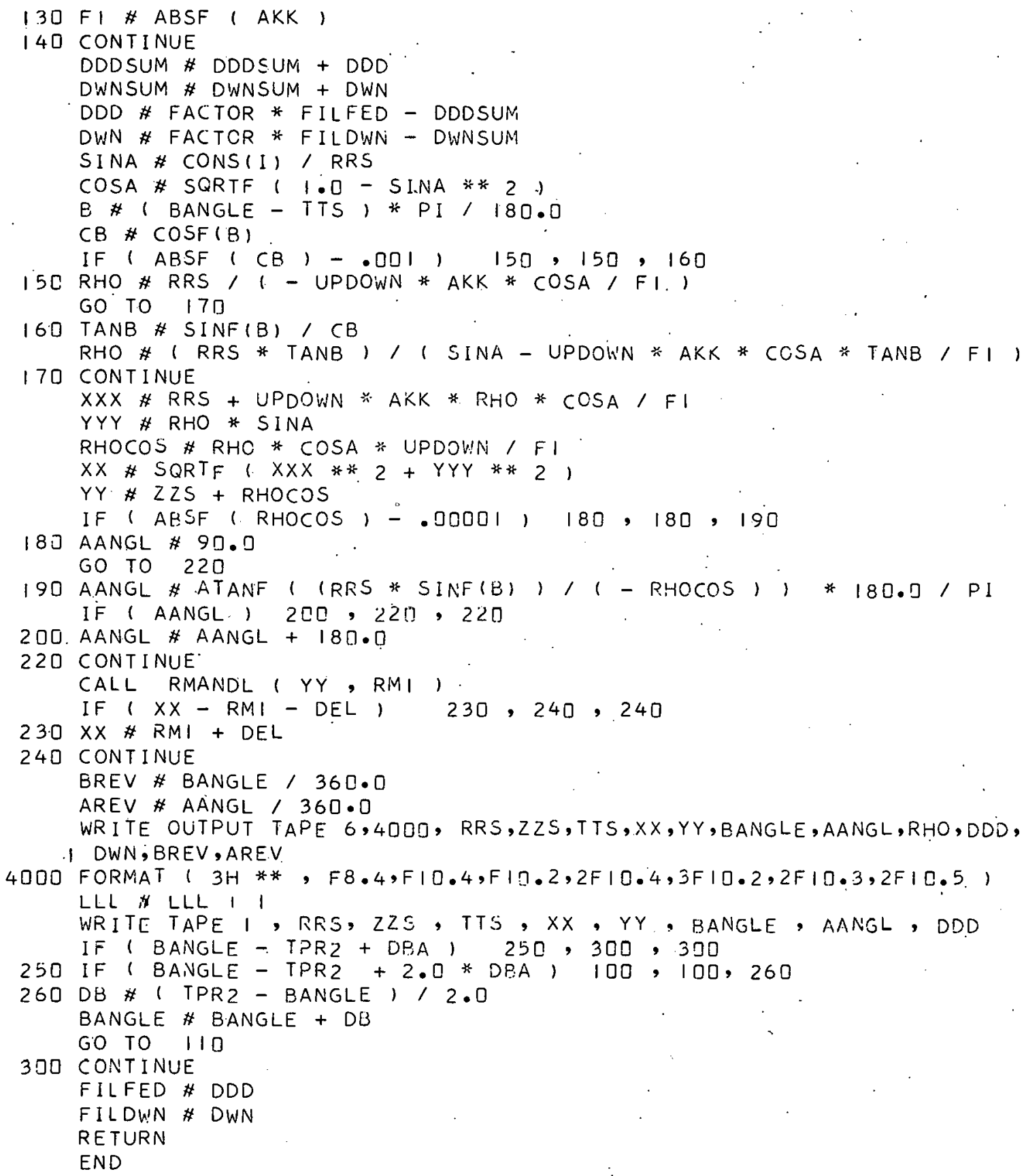

* LABEL

\section{Subroutine BLKDLT}

CBLKDLT DELETE BLOCKS THAT ARE TOO SNALL SUBROUTINE BLKDLT ( NOPTS ,

DELMIN \#5.0

REWIND I

$N \# 1$

READ TAPE I, RR, ZZ,TT, XOLD,YOLD,BOLD, AOLD 


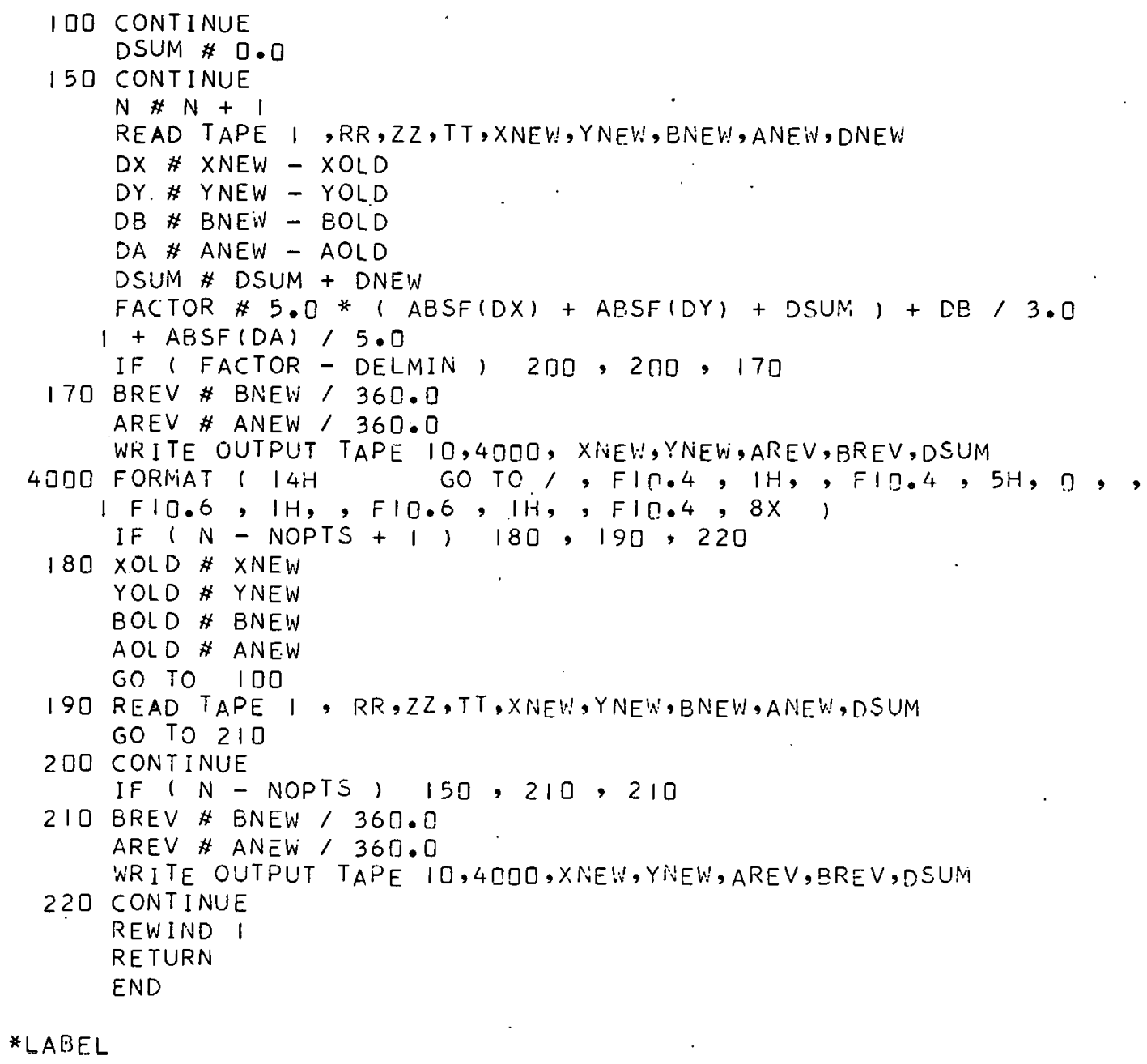

\section{Subroutine RMANDI}

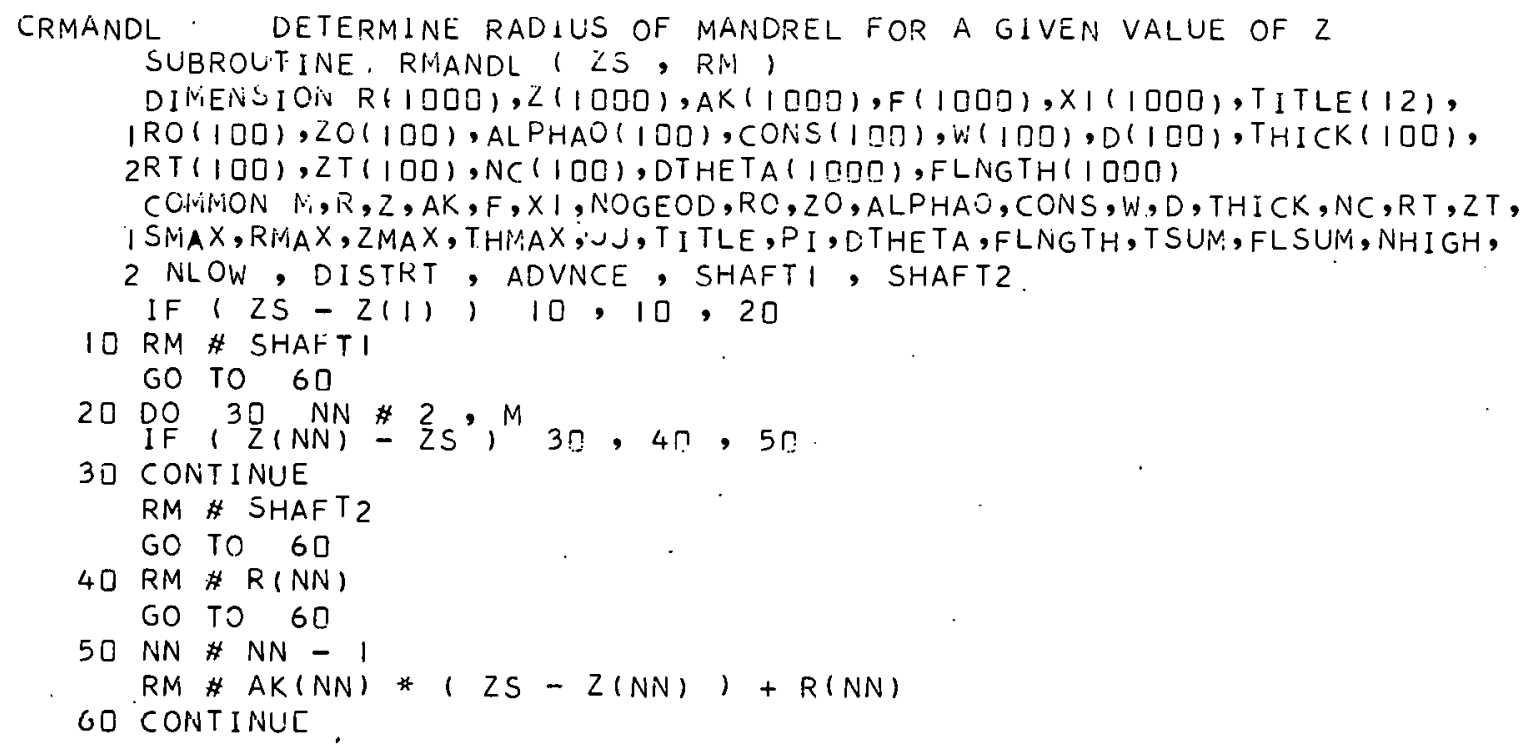


RETURN

END

* LABEL

\section{Subroutine TZZPPT}

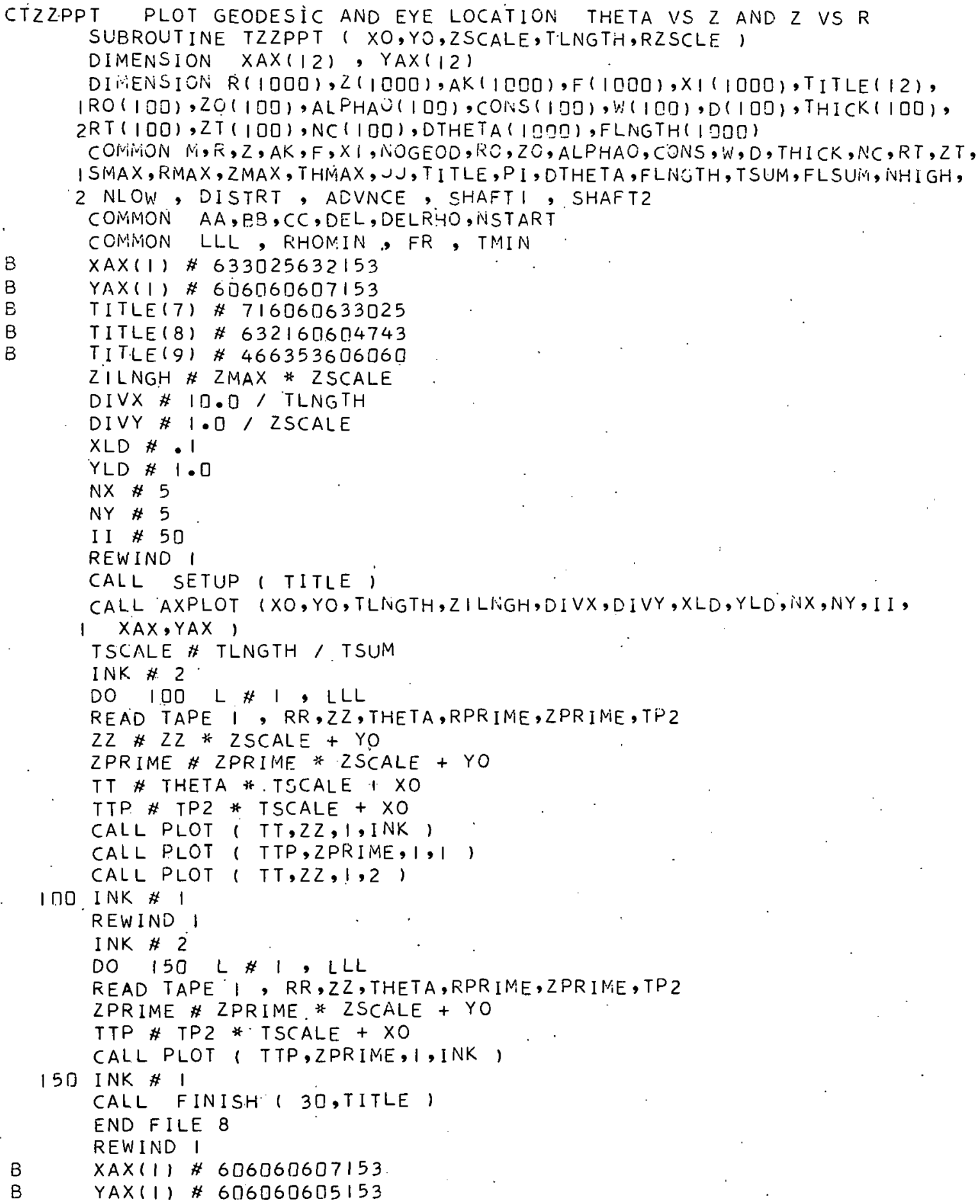




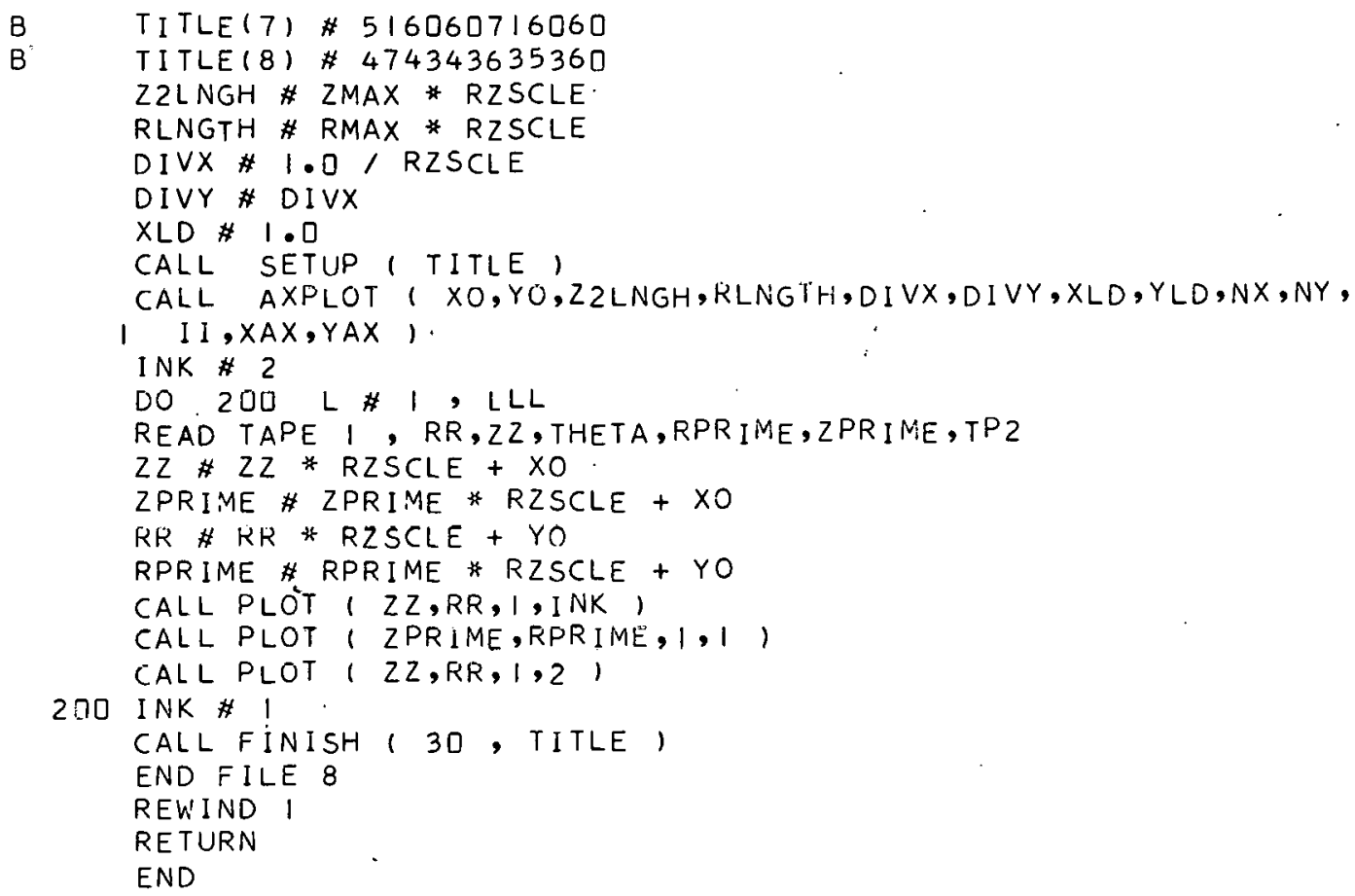

\section{Subroutine AXPLOT}

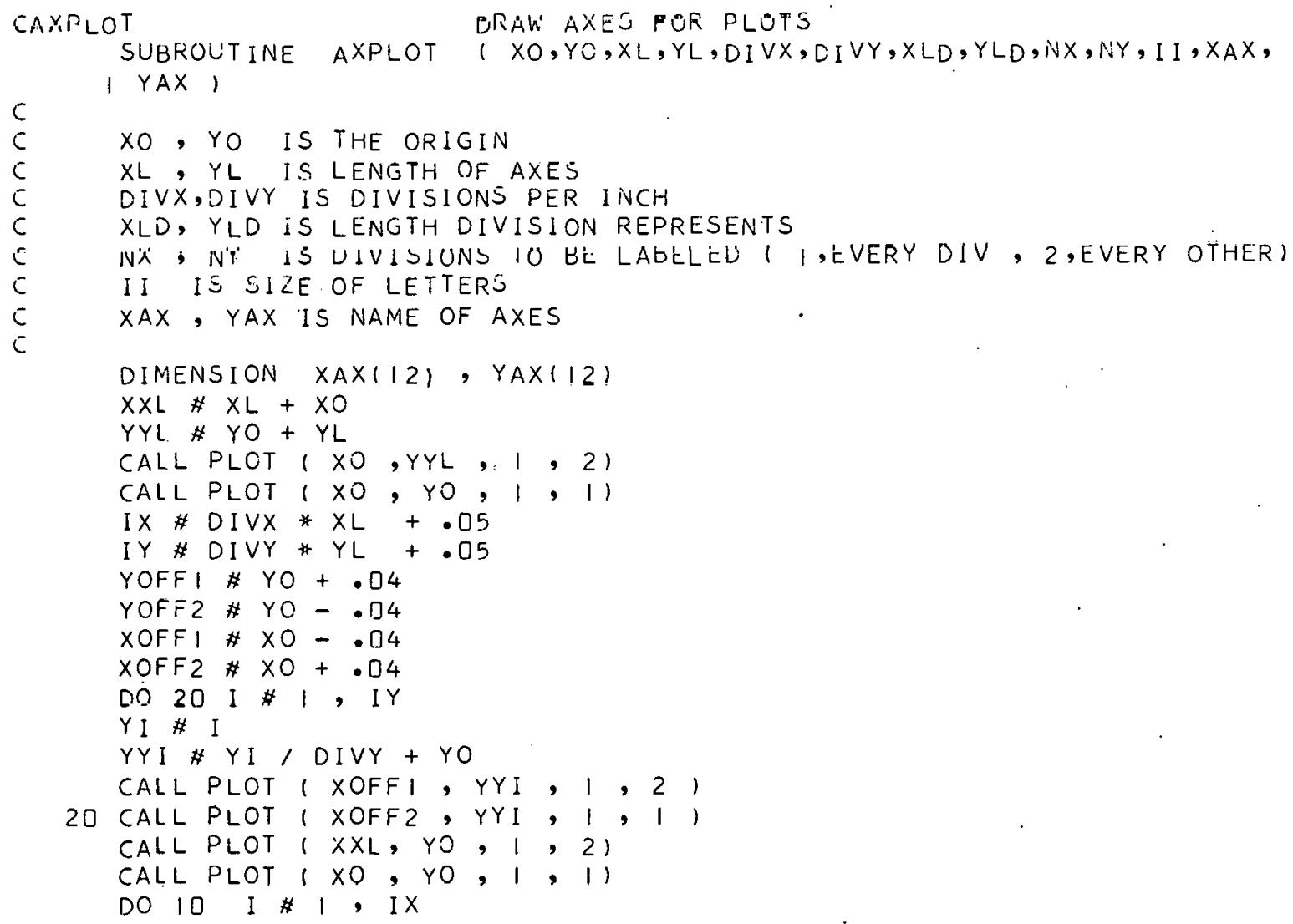




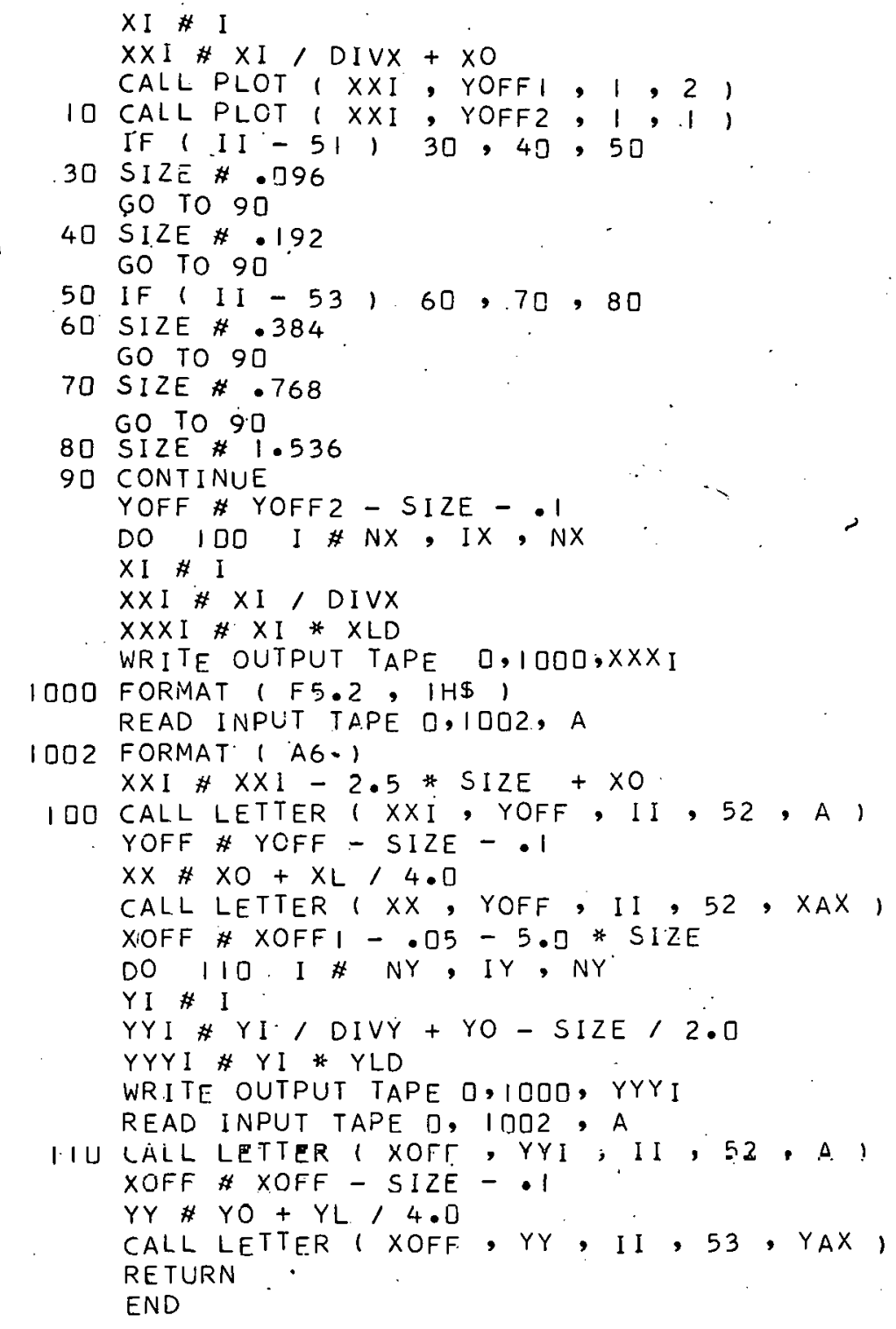

* LABEL 